\title{
Concentrically Loaded Circular RC Columns Partially Confined with FRP
}

CrossMark

\author{
Sahar Y. Ghanem ${ }^{1 *}$ and Issam E. Harik²
}

\begin{abstract}
Wrapping reinforced concrete (RC) columns with fiber reinforced polymer (FRP) composites is effective in increasing their capacity. The current state of the art concentrates primarily on fully wrapped columns and few studies dealt with partially wrapped ones. The objective herein is to evaluate the effectiveness of partial wraps (or strips) and to develop a confined concrete compressive stress-strain $\left(f_{c}-\varepsilon_{c}\right)$ model that accounts for partial wrapping. Three-dimensional finite element (FE) models are generated to evaluate the influence of different parameters on the behavior of concentrically loaded RC circular columns that are partially and fully wrapped with FRP. The results indicated an increase in ductility as the number of FRP strips is increased, and revealed that longitudinal steel had little influence on the confined $f_{c}-\varepsilon_{c}$ relationship. The proposed $f_{c}-\varepsilon_{c}$ model, derived from the parametric study, accounts for the effect of partial and full confinement, the unconfined concrete strength $f_{c^{\prime}}^{\prime}$ and yielding of transverse steel. Comparison of the results generated using the proposed model with FE and experimental results are in good agreement.
\end{abstract}

Keywords: reinforced concrete, columns, confinement, stress-strain, finite element, ductility

\section{Introduction}

The application of fiber reinforced polymer (FRP) wraps to reinforced concrete (RC) columns is an established and efficient technique for enhancing the capacity of columns. Columns that are fully wrapped with FRP showed an increase in ductility, moment and ultimate compressive load capacity, ultimate deformability and energy absorption compared to unconfined columns (Mirmiran and Shahawy 1997; Toutanji 1999). Several studies focusing on fully wrapped FRP confined concrete columns have been carried out to generate models for predicting their behavior (Nanni and Bradford 1995; Lam and Teng 2003; El Fattah and Rasheed 2015). Research on columns partially wrapped with FRP sheets (or strips) is very limited (Saadatmanesh et al. 1994; Barros and Ferreira 2008; Wu et al. 2009). Most of the studies did not account for the influence of the existing steel reinforcement on the column's behavior (Lam and Teng 2003), or simply estimate the total confinement pressure as the sum of the

\footnotetext{
${ }^{*}$ Correspondence: sayghanem@yahoo.com

${ }^{1}$ Morehead State University, Engineering and Technology Management, Morehead, KY 40351, USA

Full list of author information is available at the end of the article

Journal information: ISSN 1976-0485 / eISSN 2234-1315
}

confinement pressure due to the external FRP jacketing and the confinement pressure due to the internal transverse steel reinforcement (Barros and Ferreira 2008; El Fattah and Rasheed 2015). Few models dealt with concrete confined by both FRP and transverse steel (Lee et al. 2010).

The focus of this paper is to better understand the influence of internal steel reinforcement and partial or full external FRP wrap/reinforcement on concrete confinement. A series of finite element (FE) models are developed to analyze the effect of the aforementioned parameters on the confined concrete column. FE models have been successfully used to simulate the behavior of RC beams (Hawileh et al. 2012; Hawileh et al. 2013) and columns (Mirmiran et al. 2000) wrapped by FRP sheets. The influence of partial wrapping on the increase in strength and ductility is evaluated. The results from the FE parametric analyses were used to derive a new confined concrete compressive stress-strain model for concentrically loaded RC circular columns that are partially and fully wrapped with FRP. 


\section{Finite Element Modeling}

The FE program ANSYS 14.0 (ANSYS 2012) is used to develop a series of 3D nonlinear models for concentrically loaded circular RC columns. The confined concrete is modeled using the Drucker-Prager yield criterion (Mirmiran et al. 2000; Wu et al. 2009), and the steel reinforcement is modeled as a bi-linear elastic-perfectly plastic material. The FRP material is modeled as a linearly elastic material. The mechanical properties of concrete, steel, and FRP are listed in Table 1. Due to symmetry, a quarter of the column cross section is modeled, the load is applied as an equivalent displacement at top of the columns. The concrete stress, $f_{c}$, is calculated by averaging stresses across the entire column cross section. Perfect bond is assumed between the FRP sheets, and FRP and concrete.

The validation of the FE model is carried out by comparing the results of the model with experimental results of two columns presented by Barros and Ferreira (2008) (Fig. 1). The columns have the same unbraced length $l_{u}=600 \mathrm{~mm}(23.62$ in.) and diameter $D=200 \mathrm{~mm}$ (7.9 in.). The 28 day compressive strength of unconfined concrete $f_{c}^{\prime}=16 \mathrm{MPa}(2.32 \mathrm{ksi})$. The tests were carried out under displacement control at a rate of $1 \mathrm{~mm} / \mathrm{min}$. Figure 1 shows the FRP wrapping arrangements and columns cross section.

\section{Partial FRP Wraps or Strips}

Nine columns are considered in the parametric study. All columns have the same unbraced length $l_{u}=600 \mathrm{~mm}$ (23.62 in.) and diameter $D=200 \mathrm{~mm}$ (7.9 in.). One column is unwrapped and is the baseline column. The other eight columns are presented in Fig. 2, one of the columns is fully wrapped (FW) and the remaining seven are partially wrapped with strips varying from one strip $\left(N_{f}=1\right)$ on column S1 to seven strips on column S7 $\left(N_{f}=7\right)$.

Table 1 Material properties and FE elements for the control (or unwrapped) column and the eight columns in Fig. 2.

\begin{tabular}{|c|c|c|c|c|c|}
\hline \multirow{2}{*}{$\begin{array}{l}\text { Material } \\
\text { Concrete }\end{array}$} & \multicolumn{4}{|c|}{ Parameter } & \multirow{2}{*}{$\begin{array}{l}\text { FE element } \\
\text { SOLID } 65\end{array}$} \\
\hline & $f_{c}^{\prime}$ & & $20.68 \mathrm{MPa}$ & 3 ksi & \\
\hline & & & $55.16 \mathrm{MPa}$ & $8 \mathrm{ksi}$ & \\
\hline & $E_{c}$ & & $21.50 \mathrm{GPa}$ & 3118 ksi & \\
\hline & & & $35.13 \mathrm{GPa}$ & 5095 ksi & \\
\hline \multirow[t]{3}{*}{ Steel } & $f_{y}$ & & $413.68 \mathrm{MPa}$ & $60 \mathrm{ksi}$ & LINK 180 \\
\hline & $A_{s}$ & $\phi 6$ & $32 \mathrm{~mm}^{2}$ & $0.05 \mathrm{in}^{2}$ & \\
\hline & & $\phi 10$ & $71 \mathrm{~mm}^{2}$ & $0.11 \mathrm{in}^{2}$ & \\
\hline \multirow[t]{3}{*}{ FRP } & $t_{f}$ & & $0.15 \mathrm{~mm}$ & 0.0059 in & SHELL 181 \\
\hline & $f_{f u}$ & & $2848 \mathrm{MPa}$ & 413 ksi & \\
\hline & $E_{f}$ & & $139 \mathrm{GPa}$ & $20,160 \mathrm{ksi}$ & \\
\hline
\end{tabular}

Each strip has a width $w_{f}=40 \mathrm{~mm}$ (1.6 in.). For the fully wrapped column, $w_{f}=l_{u}$ and $N_{f}=1$. The full wrap and each strip has four layers of CFRP fabric $\left(n_{f}=4\right)$, and the thickness of each layer $t_{f}=0.15 \mathrm{~mm}$ (0.0059 in.). The FRP volumetric ratio $\left(\rho_{f}\right)$ for each column is determined as follows

$$
\rho_{f}=4 \frac{n_{f} w_{f} N_{f} t_{f}}{D l_{u}}
$$

Four groups of columns (Table 2) are studied to evaluate the influence of different parameters on the confined concrete stress $\left(f_{c}\right)$, axial strain $\left(\varepsilon_{c}\right)$ and lateral strain $\left(\varepsilon_{l}\right)$. In addition to the unwrapped column, each group contains the eight columns in Fig. 2, and Group 1 is the baseline group. In Groups 2-4, three different parameters are varied: the 28 day compressive strength of unconfined concrete $f_{c}^{\prime}$, the transverse steel reinforcement ratio, $\rho_{s t}$, and the longitudinal steel reinforcement ratio, $\rho_{s l}$, respectively (Eq. 2)

$$
\rho_{s t}=V_{s t} / V_{c}, \rho_{s l}=A_{s l} / A_{g}
$$

where $V_{s t}$ is the volume of transverse steel; $V_{c}$ is the volume of concrete; $A_{s l}$ is the total area of longitudinal steel; and $A_{g}$ is the gross area of the column section.

Figure 3 presents the results for all four groups in term of compressive stress of confined concrete $\left(f_{c}\right)$ versus concrete axial strain $\left(\varepsilon_{c}\right)$ and concrete lateral strain $\left(\varepsilon_{l}\right)$.

Figure 4 presents the variation in the strength ratio $\left(f_{c c}^{\prime} / f_{c}^{\prime}\right)$, strain ratio $\left(\varepsilon_{c c u} / \varepsilon_{c}^{\prime}\right)$ and ductility factor $(\mu) . f_{c c}^{\prime}$ is the ultimate confined concrete compressive stress; $\varepsilon_{c c u}$ is the ultimate confined concrete axial strain corresponding to the ultimate confined concrete compressive stress; $\varepsilon_{c}^{\prime}$ is the concrete axial strain at the unconfined concrete compressive strength $\left(f_{c}^{\prime}\right)$. The numerical values of these terms are listed in Table 3 for all Groups. The derivation of the ductility factor is based on the one proposed by Cui and Sheikh (2010).

Three efficiency factors, $\beta$, are introduced in Eq. 3 and Fig. 4 to compare the fully wrapped (FW) columns to unwrapped columns (UW) in each group.

$$
\beta_{\mu}=\frac{\mu_{F W}}{\mu_{U W}} ; \beta_{\varepsilon}=\frac{\left(\varepsilon_{c c u}\right)_{F W}}{\left(\varepsilon_{c c u}\right)_{U W}} \text { and } \beta_{f}=\frac{\left(f_{c c}^{\prime}\right)_{F W}}{\left(f_{c c}^{\prime}\right)_{U W}}
$$

For Fig. 4, refer to Table 2 for information on Groups 1 to 4 , and to Fig. 2 for $\rho_{f}$ values

\subsection{FRP Volumetric Ratio, $\rho_{f}$}

In all column groups, as the FRP volumetric ratio in Eq. 1 increases from $\rho_{f}=0.0$ for the unwrapped column to $\rho_{f}=0.012$ for the fully wrapped column (Fig. 3), and as expected, there is an increase in the ultimate confined 


$$
\begin{array}{ll}
f_{c}^{\prime}=16 \mathrm{MPa} & (2.32 \mathrm{ksi}) \\
f_{y}=468.3 \mathrm{MPa} & (68 \mathrm{ksi}) \\
f_{f u}=3539 \mathrm{MPa} & (513.3 \mathrm{ksi}) \\
E_{f}=232 \mathrm{GPa} & (33649 \mathrm{ksi})
\end{array}
$$

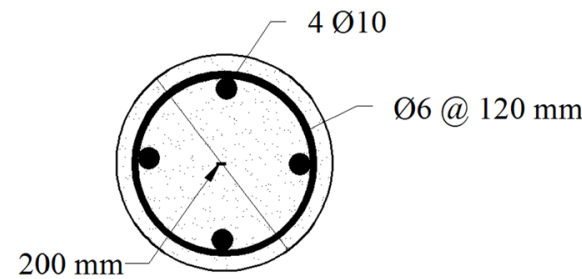

0.03

0.04

0.05

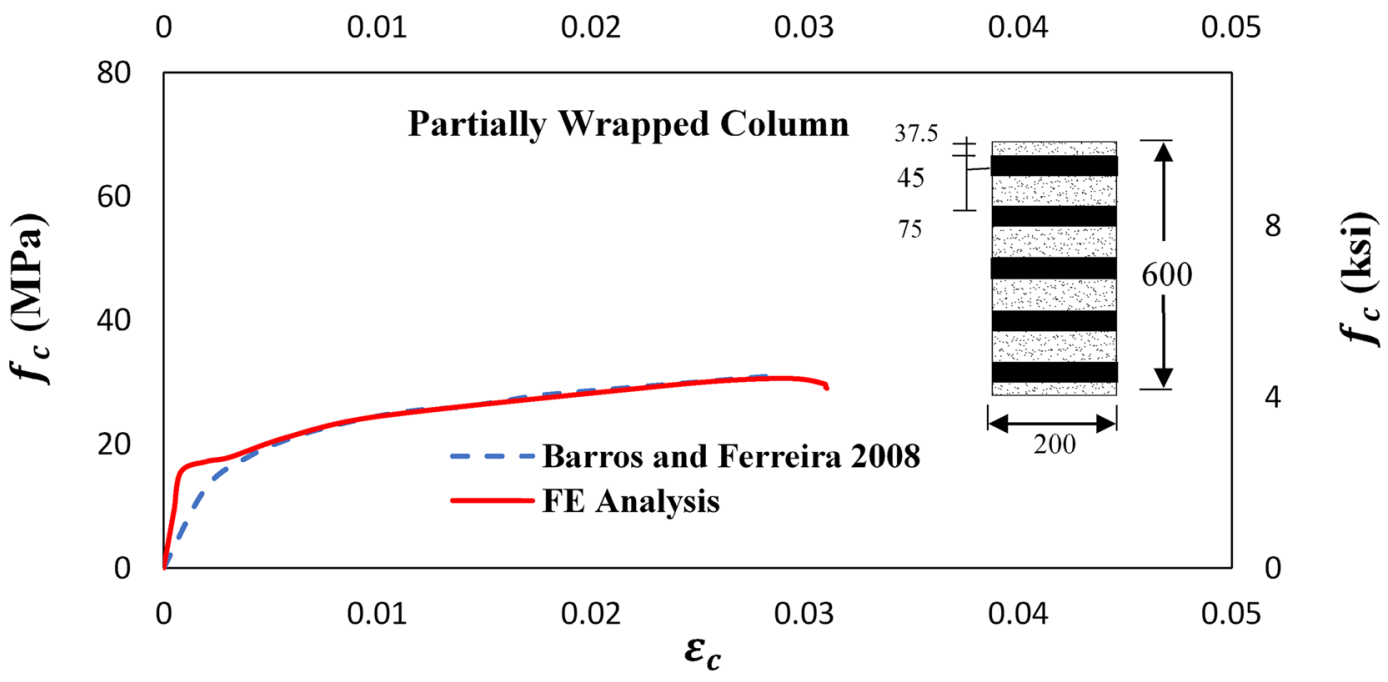

(a)

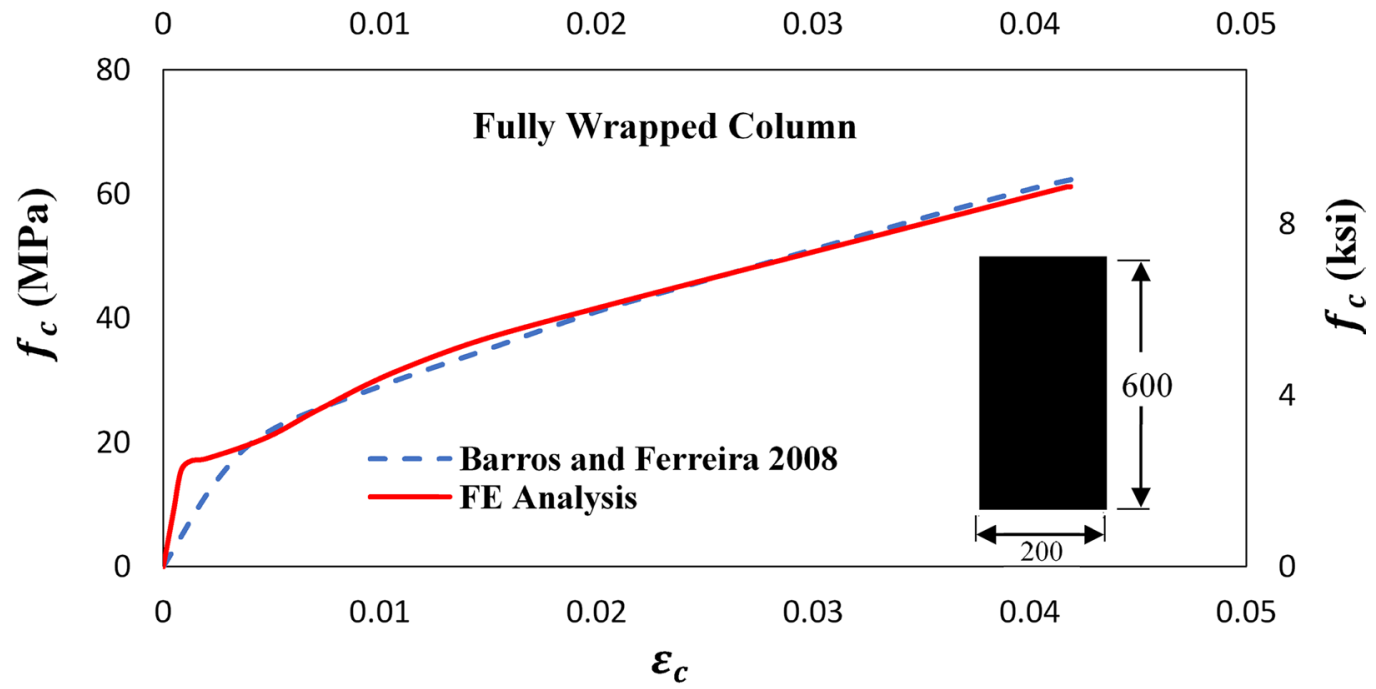

(b)

Fig. 1 Comparison of compressive stress $\left(f_{c}\right)$ versus axial strain $\left(\varepsilon_{c}\right)$ between FE and experimental results: a partially wrapped column and $\mathbf{b}$ fully wrapped column (all dimensions are in $\mathrm{mm} ; 1 \mathrm{~mm}=0.039 \mathrm{in}$.).

concrete compressive stress $\left(f_{c c}^{\prime}\right)$, the ultimate confined axial strain $\left(\varepsilon_{c c u}\right)$, and the ultimate lateral strain of confined concrete $\left(\varepsilon_{l u}\right)$. Figure 4 and Table 3 provide more detailed results that clearly show the influence of the number of strips in Groups 1-4 on the strength ratio $\left(f_{c c}^{\prime} / f_{c}^{\prime}\right)$, strain ratio $\left(\varepsilon_{c c u} / \varepsilon_{c}^{\prime}\right)$, and ductility factor $(\mu)$. As the number of strips is increased, the aforementioned ratios also increase. 


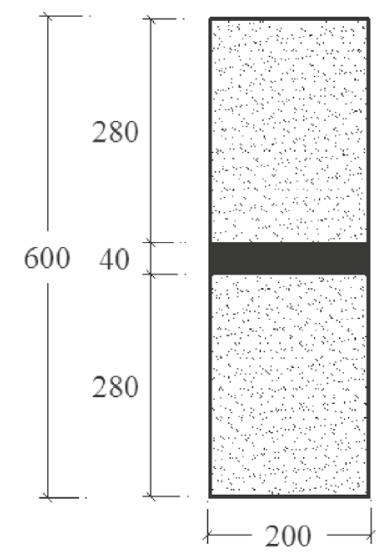

1 Strip (S1) $\rho_{f}=\mathbf{0 . 0 0 0 8}$

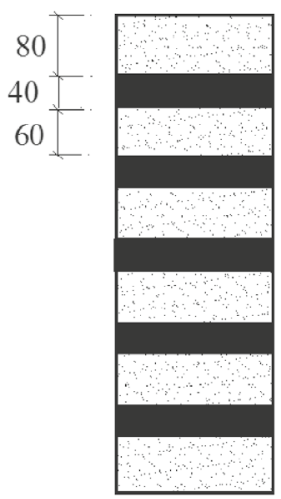

5 Strips (S5) $\rho_{f}=\mathbf{0 . 0 0 4}$

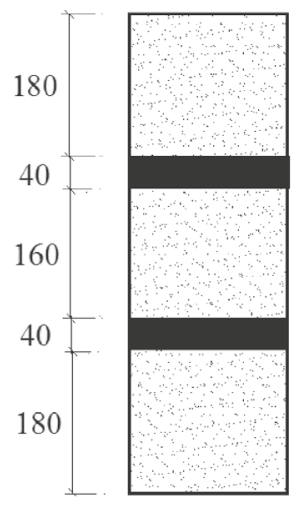

2 Strips (S2)

$\rho_{f}=\mathbf{0 . 0 0 1 6}$
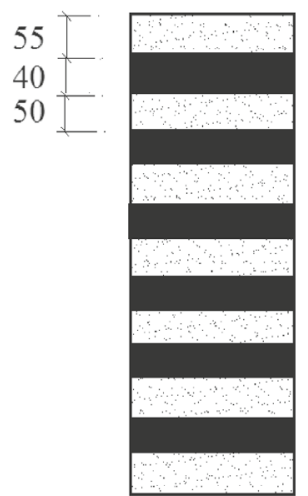

40

40

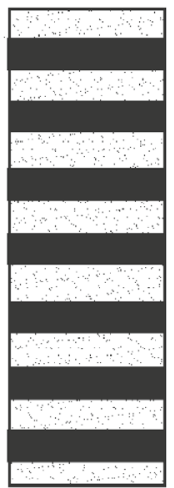

7 Strips (S7)

$\rho_{f}=\mathbf{0 . 0 0 5 6}$

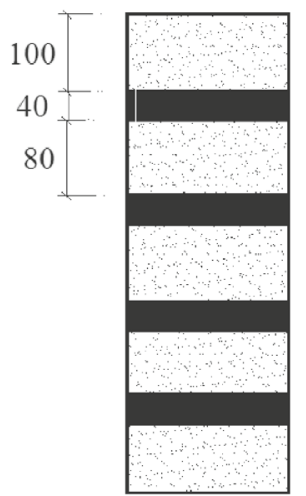

4 Strips (S4)

$\rho_{f}=\mathbf{0 . 0 0 3 2}$

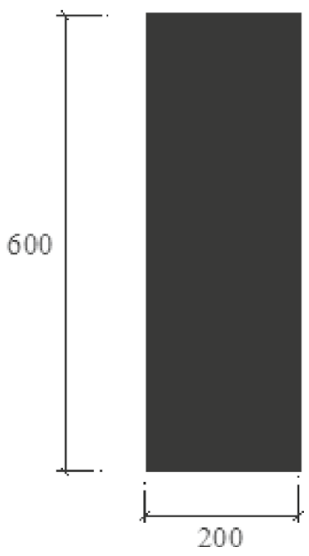

Full Wrap (FW)

$\rho_{f}=\mathbf{0 . 0 1 2}$

Fig. 2 FRP wrap layout on circular columns (all dimensions are in $\mathrm{mm} ; 1 \mathrm{~mm}=0.039$ in.).

Table 2 Column groups used in the parametric study.

\begin{tabular}{|c|c|c|c|c|c|c|c|}
\hline \multirow[t]{3}{*}{ Group\# $^{a}$} & \multicolumn{2}{|l|}{$f_{c}^{\prime}$} & \multicolumn{2}{|c|}{$\begin{array}{l}\text { Longitudinal steel } \\
\phi 10 \mathrm{~mm}(\# 3)\end{array}$} & \multicolumn{3}{|c|}{$\begin{array}{l}\text { Transverse steel stirrups } \\
\phi 6 \mathrm{~mm}(\# 2)\end{array}$} \\
\hline & \multirow[t]{2}{*}{$\mathrm{MPa}$} & \multirow[t]{2}{*}{ ksi } & \multirow[t]{2}{*}{ Number of bars } & \multirow[t]{2}{*}{$\rho_{s l}$} & \multicolumn{2}{|c|}{ Spacing } & \multirow[t]{2}{*}{$\rho_{s t}$} \\
\hline & & & & & $\mathrm{mm}$ & in & \\
\hline 1 & 20.68 & 3 & 4 & 0.011 & 140 & 5.50 & 0.004 \\
\hline 2 & 55.16 & 8 & 4 & 0.011 & 140 & 5.50 & 0.004 \\
\hline 3 & 20.68 & 3 & 4 & 0.011 & 80 & 3.15 & 0.0064 \\
\hline 4 & 20.68 & 3 & 12 & 0.027 & 140 & 5.50 & 0.004 \\
\hline
\end{tabular}

a Each group contains, in addition to the unwrapped column, the eight columns in Fig. 2. 


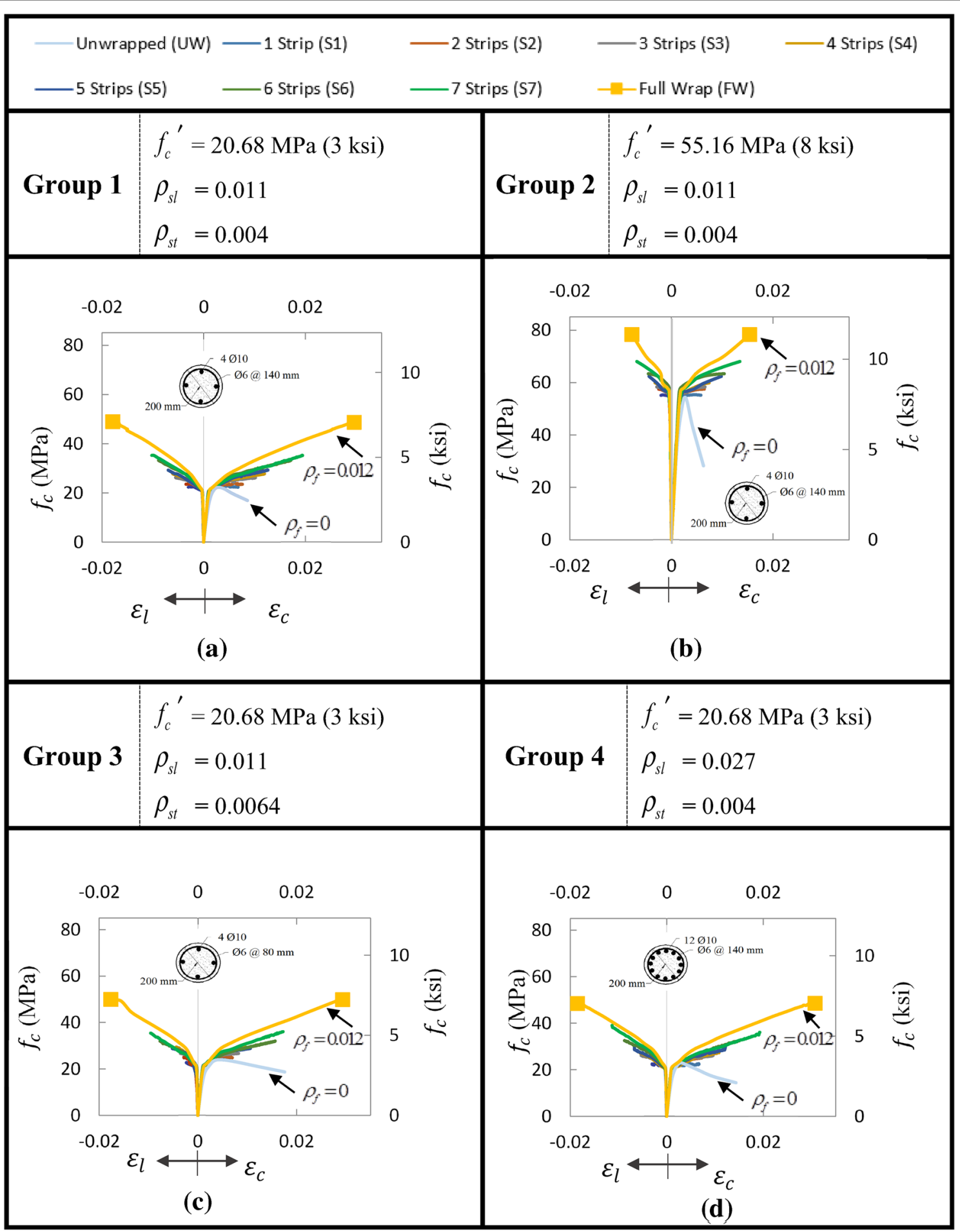

Fig. 3 Comparison of compressive stress $\left(f_{c}\right)$ vs. axial strain $\left(\varepsilon_{c}\right)$ and lateral strain $\left(\varepsilon_{1}\right)$ for the columns in a Group 1, b Group 2, c Group 3, and d Group 4. Note Refer to Fig. 2 for $\rho_{f}$ values. 


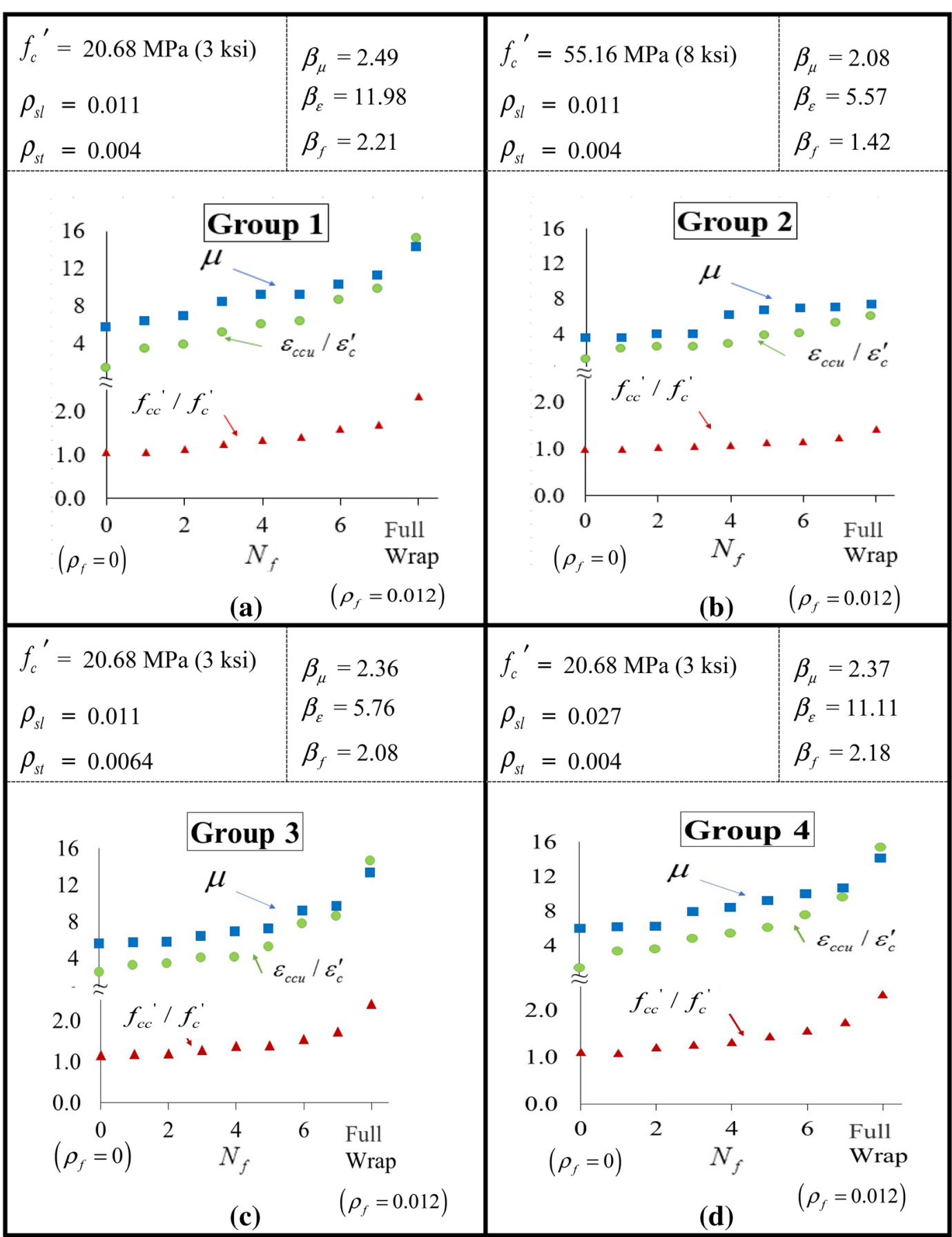

Fig. 4 Strength ratio $\left(f_{c c}^{\prime} / f_{c}^{\prime}\right)$, strain ratio $\left(\varepsilon_{c c u} / \varepsilon_{c}^{\prime}\right)$, and ductility factor $(\mu)$ vs number of strips $\left(N_{f}\right)$ for the columns in a Group 1, b Group 2, c Group 3, and d Group 4.

3.2 Unconfined Concrete Compressive Strength, $f_{c}^{\prime}$ The influence of $f_{c}^{\prime}$ is studied by comparing Group 1 (Figs. $3 \mathrm{a}$ and $4 \mathrm{a}$, and Table 3 ) and Group 2 (Figs. $3 \mathrm{~b}$ and $4 \mathrm{~b}$, and Table 3 ). These Figures show the increase in ultimate confined concrete compressive stress $\left(f_{c c}^{\prime}\right)$ and the reduction in the ultimate confined axial strain $\left(\varepsilon_{c c u}\right)$ as the unconfined concrete compressive strength $f_{c}^{\prime}$ is increased. All nine columns in Group 1 (Figs. 3a and 4a, and Table 3) have strength ratios $\left(f_{c c}^{\prime} / f_{c}^{\prime}\right)$, strain ratios $\left(\varepsilon_{c c u} / \varepsilon_{c}^{\prime}\right)$, ductility factors $(\mu)$, and efficiency factors, $\beta$ 
Table 3 Stresses, strains and ductility factors for the unwrapped columns (UW) and columns in Groups 1-4 (1 $\mathrm{MPa}=0.145 \mathrm{ksi}$ ).

\begin{tabular}{|c|c|c|c|c|c|c|c|c|c|c|}
\hline \multicolumn{2}{|c|}{ Group\# $^{a}$} & \multicolumn{9}{|c|}{ Columns $^{\mathrm{a}}$} \\
\hline & & UW & S1 & S2 & S3 & S4 & S5 & S6 & S7 & $\mathrm{FW}$ \\
\hline \multirow[t]{6}{*}{1} & $f_{C C}^{\prime}(\mathrm{MPa})$ & 22.13 & 22.32 & 23.51 & 26.22 & 27.81 & 29.23 & 33.18 & 35.24 & 48.80 \\
\hline & $\varepsilon_{c c u}$ & 0.0025 & 0.0068 & 0.0076 & 0.0102 & 0.0120 & 0.0126 & 0.0171 & 0.0195 & 0.0303 \\
\hline & $\varepsilon_{l u}$ & - & 0.003 & 0.0035 & 0.0055 & 0.0061 & 0.0070 & 0.0089 & 0.0102 & 0.0179 \\
\hline & $f_{c c}^{\prime} / f_{c}^{\prime}$ & 1.079 & 1.070 & 1.137 & 1.268 & 1.345 & 1.414 & 1.604 & 1.704 & 2.360 \\
\hline & $\varepsilon_{c c u} / \varepsilon_{c}^{\prime}$ & 1.266 & 3.390 & 3.808 & 5.088 & 5.995 & 6.321 & 8.562 & 9.741 & 15.166 \\
\hline & $\mu$ & 5.744 & 6.357 & 6.952 & 8.422 & 9.215 & 9.219 & 10.269 & 11.266 & 14.327 \\
\hline \multirow[t]{6}{*}{2} & $f_{c C}^{\prime}(\mathrm{MPa})$ & 55.20 & 55.22 & 57.52 & 28.35 & 59.86 & 62.35 & 63.39 & 68.06 & 78.27 \\
\hline & $\varepsilon_{c c u}$ & 0.0028 & 0.0058 & 0.0065 & 0.0066 & 0.0074 & 0.0098 & 0.0104 & 0.0135 & 0.0154 \\
\hline & $\varepsilon_{l u}$ & - & 0.0021 & 0.0025 & 0.0029 & 0.0032 & 0.0044 & 0.0045 & 0.0068 & 0.0077 \\
\hline & $f_{c c}^{\prime} / f_{c}^{\prime}$ & 1.001 & 1.001 & 1.043 & 1.058 & 1.085 & 1.130 & 1.149 & 1.234 & 1.419 \\
\hline & $\varepsilon_{c c u} / \varepsilon_{c}^{\prime}$ & 1.083 & 2.267 & 2.534 & 2.580 & 2.903 & 3.840 & 4.062 & 5.273 & 6.036 \\
\hline & $\mu$ & 3.53 & 3.552 & 3.970 & 4.041 & 6.177 & 6.762 & 6.915 & 7.087 & 7.339 \\
\hline \multirow[t]{6}{*}{3} & $f_{c C}^{\prime}(\mathrm{MPa})$ & 23.89 & 24.55 & 24.78 & 26.65 & 28.80 & 28.83 & 32.04 & 35.99 & 49.79 \\
\hline & $\varepsilon_{c c u}$ & 0.0051 & 0.0066 & 0.0070 & 0.0083 & 0.0084 & 0.0106 & 0.0157 & 0.0173 & 0.0294 \\
\hline & $\varepsilon_{/ u}$ & - & 0.0023 & 0.0028 & 0.0035 & 0.0044 & 0.0052 & 0.0077 & 0.0096 & 0.0178 \\
\hline & $f_{c c}^{\prime} / f_{c}^{\prime}$ & 1.155 & 1.187 & 1.198 & 1.289 & 1.393 & 1.394 & 1.549 & 1.740 & 2.408 \\
\hline & $\varepsilon_{c c u} / \varepsilon_{c}^{\prime}$ & 2.554 & 3.313 & 3.491 & 4.129 & 4.194 & 5.309 & 7.841 & 8.650 & 14.717 \\
\hline & $\mu$ & 5.674 & 5.796 & 5.813 & 6.446 & 6.983 & 7.315 & 9.271 & 9.765 & 13.426 \\
\hline \multirow[t]{6}{*}{4} & $f_{c c}^{\prime}(\mathrm{MPa})$ & 22.2 & 22.38 & 25.02 & 26.22 & 27.31 & 29.89 & 32.54 & 36.16 & 48.49 \\
\hline & $\varepsilon_{c c u}$ & 0.0028 & 0.0066 & 0.0072 & 0.0096 & 0.0108 & 0.0122 & 0.0150 & 0.0193 & 0.0307 \\
\hline & $\varepsilon_{/ u}$ & - & 0.0031 & 0.0033 & 0.0053 & 0.0056 & 0.0067 & 0.0088 & 0.0113 & 0.0187 \\
\hline & $f_{c c}^{\prime} / f_{c}^{\prime}$ & 1.074 & 1.082 & 1.210 & 1.268 & 1.320 & 1.445 & 1.573 & 1.749 & 2.345 \\
\hline & $\varepsilon_{c c u} / \varepsilon_{c}^{\prime}$ & 1.384 & 3.323 & 3.618 & 4.795 & 5.391 & 6.082 & 7.527 & 9.637 & 15.374 \\
\hline & $\mu$ & 5.972 & 6.205 & 6.231 & 7.918 & 8.415 & 9.206 & 10.026 & 10.697 & 14.155 \\
\hline
\end{tabular}

a Refer to Tables 1 and 2, and Fig. 2 for column dimensions and properties.

(Eq. 3), larger than the one for the corresponding columns in Group 2 (Figs. 3b and 4b, and Table 3). For column $\mathrm{S} 1$, the concrete stress-strain $\left(f_{c}-\varepsilon_{c}\right)$ relationship is presented in Fig. 5a for Groups 1-4 to show the influence of the different parameters.

In order to graphically evaluate the influence of the other parameters $\left(\rho_{s t}\right.$ and $\left.\rho_{s l}\right)$ on $f_{c c}^{\prime}$, the results for Group 2 are removed from Fig. 5b for column S1, Fig. 6a for column S4, and Fig. $6 \mathrm{~b}$ for the FW column.

\subsection{Transverse Steel Reinforcement Ratio, $\rho_{\text {st }}$}

The influence of $\rho_{s t}$ is studied by comparing the columns in Group 1 (Fig. 3a and Table 3), with $\rho_{s t}=0.004$, and Group 3 (Fig. 3c and Table 3) with $\rho_{s t}=0.0064$. Except for columns S5 and S6, the columns in Group 1 have a lower ultimate confined concrete compressive stress $f_{c c}^{\prime}$. For columns S5 and S6 in Group 3, there is an overlap between the FRP and transverse steel leading to a decrease in the volume of confined concrete, and in turn to a lower $f_{c c}^{\prime}$. The columns in Group 1 also have a higher ultimate confined concrete axial strain, $\varepsilon_{c c u}$, compared to the ones in Group 3 (Table 3). The ductility factor, $\mu$, and the efficiency factors, $\beta$ in Eq. 3 , are reduced by increasing $\rho_{s t}$ (Table 3 and Fig. 4). The influence of increasing $\rho_{s t}$ on $f_{c c}^{\prime}$ can be seen in Fig. 5b for the column with one strip (S1), in Fig. 6a for the column with four strips (S4), and in Fig. $6 \mathrm{~b}$ for the fully wrapped column.

\subsection{Longitudinal Steel Reinforcement Ratio, $\rho_{s l}$}

The effect of $\rho_{s l}$ is studied by comparing the columns in Group $1\left(\rho_{s l}=0.011\right)$ and Group $4\left(\rho_{s l}=0.027\right)$ in Figs. $4 \mathrm{a}$, $\mathrm{d}, 5 \mathrm{~b}$ and 6 and Table 3. At ultimate conditions, the columns in Group 1 have a slightly lower ultimate confined concrete compressive stress and higher ultimate axial concrete strain (Table 3). The efficiency factors, $\beta$ (Eq. 3), for Group 1 are slightly larger than the ones for Group 4 (Fig. 4a and $4 \mathrm{~d}$ ). In general, the change in the strength ratios $\left(f_{c c}^{\prime} / f_{c}^{\prime}\right)$, strain ratios $\left(\varepsilon_{c c u} / \varepsilon_{c}^{\prime}\right)$, and ductility factors $(\mu)$, due to the increase in the longitudinal steel reinforcement ratio has a little influence on concrete confinement for the columns under consideration (Figs. $4 \mathrm{a}$ and d, $5 \mathrm{~b}$ and 6). Figures 5 and 6 clearly show that the $f_{c}-\varepsilon_{c}$ plots 


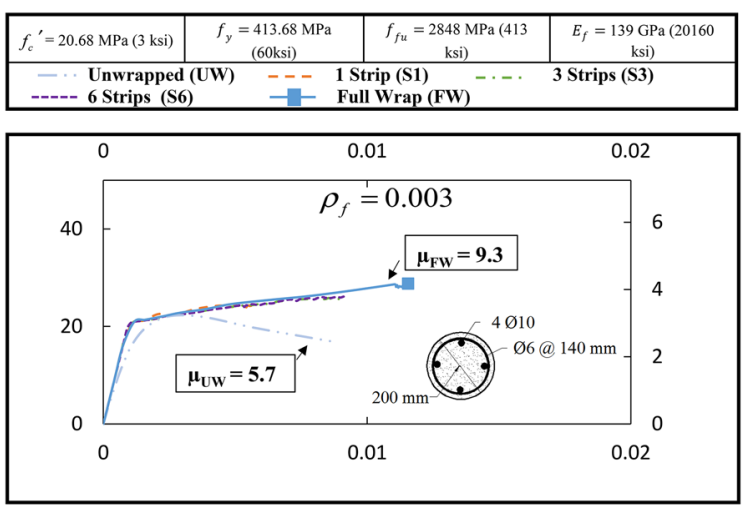

(a)

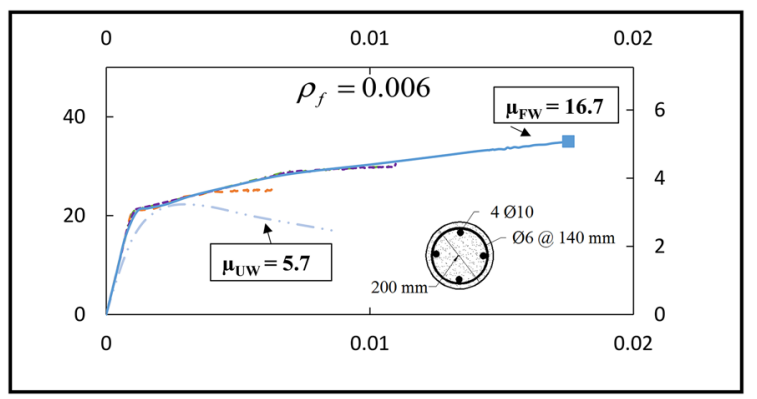

(b)

Fig. 5 Comparison of compressive stress $\left(f_{c}\right)$ versus axial strain $\left(\varepsilon_{c}\right)$ for the column with 1-Strip (S1 in Fig. 2) for: $\mathbf{a}$ Groups 1-4 and $\mathbf{b}$ for Groups 1, 3 and 4 (Table 2).

for Groups 1 and 4 are difficult to separate. Consequently, the contribution of the longitudinal steel is neglected in the derivation of the confined concrete stress-strain model in the following sections.

\subsection{Strip Arrangement}

The effect of the number of strips on the behavior of confined columns is evaluated in Fig. 7 for two FRP volumetric ratios, $\rho_{f}=0.003$ and $\rho_{f}=0.006$ (Eq. 1). One unwrapped $\left(\rho_{f}=0.0\right)$ and one fully wrapped column, and three columns wrapped with 1,3 , and 6 strips are compared in Fig. 7. All columns have the same cross section and material properties as the columns in Group 1 (Table 2). In order to maintain a constant FRP ratio, $\rho_{f}$, the thickness, $t_{f}$, and/or number of FRP sheets per strip, $n_{f}$ is varied to achieve different strip arrangements. Figure 7 clearly shows that, for the same volume of CFRP material bonded to the column, the fully wrapped is more effective in increasing the ultimate compressive stress and strain, and thus, ductility. The effectiveness is more pronounced when the CFRP volumetric ratio is increased to 0.006 in Fig. 7b. The increase in the number of strips, from 1 to 6, leads to an increase in the ultimate compressive stress and strain, and ductility. Although the fully wrapped column is more effective, in certain instances, a specific number of strips could satisfy the design requirements. This may be of interest when retrofitting columns that are not easily accessible (e.g. over a waterway) where the placement of strips maybe more economical than placing a full wrap.

\section{Current FRP Confined Concrete Stress-Strain Models}

A number of models are available in the literature for the confined concrete stress-strain relationships (Richard and Abbott 1975; Mander et al. 1988; Pellegrino and Modena 2010). The following three models are highlighted in this section and in more details in Fig. 8 and Table 4. They are used for comparison with the proposed model presented in the following section.

Lam and Teng's (2003) stress-strain model (Fig. 8a) accounts for FRP confinement only. Pellegrino and Modena (2010) proposed an analytical model (Fig. 8b) for partially wrapped columns. The model is based on Richard and Abbott's model (1975) that accounts for steel reinforcement contribution to confinement in circular and rectangular columns. The partial wraps are accounted for by modifying the discontinuity coefficient used for transverse steel in Mander's model (1988). The total lateral confining pressure, $f_{l}$, is derived by combining that of the transverse steel and FRP. Lee et al. (2010) introduced an empirical model for concrete confined with both steel spirals and FRP wraps (Fig. 8c). The model accounts for yielding of transverse steel and its contribution to the confining pressure.

\section{Proposed Confined $f_{c}-\varepsilon_{c}$ Model}

Richard and Abbott's model (1975), a bilinear model that has been adopted and modified by others for concrete columns confined by FRP (Wu et al. 2009; Pellegrino and Modena 2010), is also adopted herein and modified based on the aforementioned parametric study. Since the contribution of longitudinal steel is minimal (Figs. 5 and 6), it is not considered in the model generation.

The proposed $f_{c}-\varepsilon_{c}$ model comprises a nonlinear portion for the strain range of $0 \leq \varepsilon_{c} \leq \varepsilon_{c, s}$ and a linear portion for $\varepsilon_{c, s}<\varepsilon_{c} \leq \varepsilon_{c c u}$ (Fig. 8d). $\varepsilon_{c, s}$ is the confined concrete axial strain at yielding of the transverse steel and $\varepsilon_{c c u}$ is the ultimate confined concrete axial strain. The $f_{c}-\varepsilon_{c}$ relationship is expressed as follows:

$$
\begin{aligned}
& f_{c}=\frac{\left(E_{c}-E_{1}\right) \varepsilon_{c}}{\left[1+\left(\frac{\left(E_{c}-E_{1}\right) \varepsilon_{c}}{f_{0}}\right)^{n}\right]^{1 / n}}+E_{1} \varepsilon_{c}^{m} \quad 0 \leq \varepsilon_{c} \leq \varepsilon_{c, s} \\
& f_{c}=f_{c, s}+E_{2}\left(\varepsilon_{c}-\varepsilon_{c, s}\right) \quad \varepsilon_{c, s} \leq \varepsilon_{c} \leq \varepsilon_{c c u}
\end{aligned}
$$




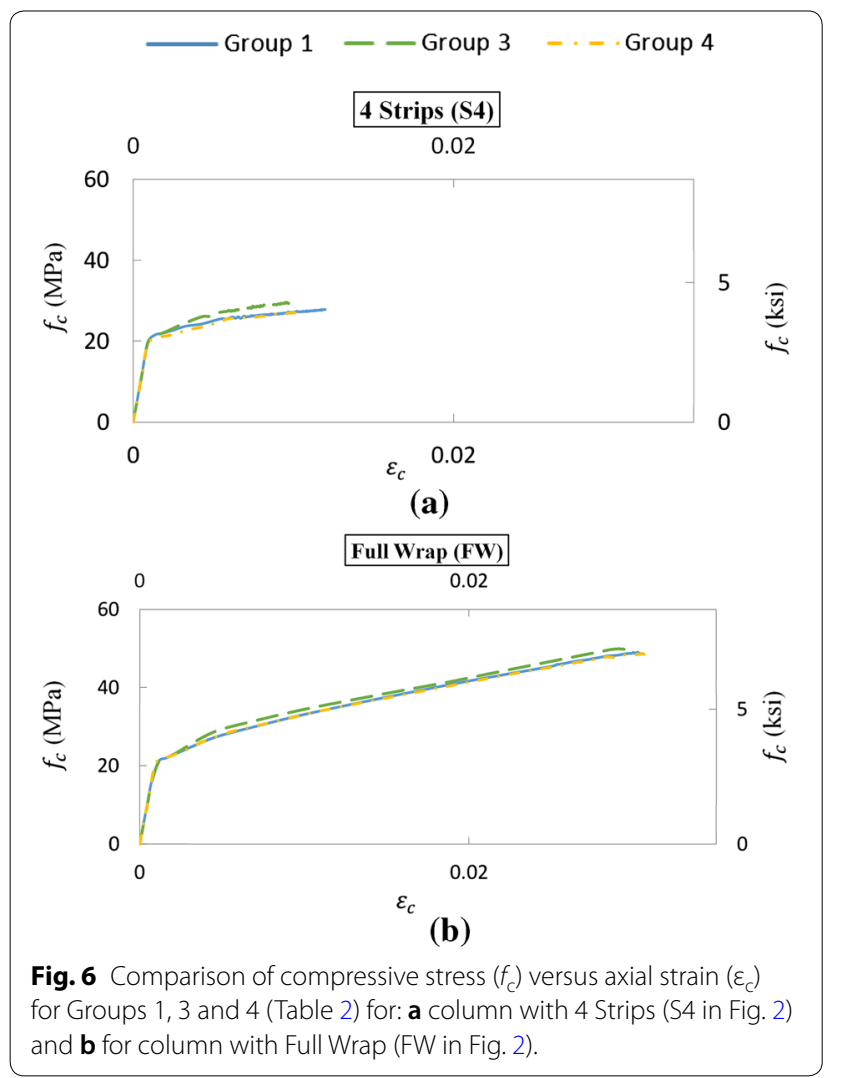

where $f_{c}$ and $\varepsilon_{c}$ are the concrete compressive stress and strain of FRP-confined concrete, respectively; $f_{0}$ is the reference plastic stress at the intercept of the slope at yielding of transverse steel with the stress axis (Fig. 8d); and $n$ is a shape parameter in the transition zone, $E_{1}$ is the slope of the stress strain curve at the yielding of transverse steel, $E_{c}$ is the concrete modulus of elasticity and, for normal-weight concrete (ACI 2011), and $E_{2}$ is the slope of the stress strain curve after yielding of transverse steel,

$$
\begin{aligned}
& n=1+\frac{1}{\left(E_{c} \varepsilon_{c}^{\prime} / f_{c}^{\prime}\right)-1} \\
& E_{c}=4700 \sqrt{f_{c}^{\prime}}(\mathrm{MPa}) \\
& E_{1}=\frac{f_{c, s}-f_{0}}{\varepsilon_{c, s}} \\
& E_{2}=\frac{f_{c c}^{\prime}-f_{c, s}}{\varepsilon_{c c u}-\varepsilon_{c, s}}
\end{aligned}
$$

where $f_{c, s}$ and $\varepsilon_{c, s}$ are the compressive stress and strain in confined concrete at yielding of transverse steel. In Eq. (4), $m$ can be determined by setting the $f_{c}\left(\varepsilon_{c, s}\right)=f_{c, s}$ at the point of yielding of transverse steel

$$
m=\left[\frac{1}{\ln \left(\varepsilon_{c, s}\right)}\right]\left\{\ln \left[\frac{1}{E_{1}}\left(f_{c, s}-\frac{\left(E_{c}-E_{1}\right) \varepsilon_{c, s}}{\left\{1+\left[\frac{\left(E_{c}-E_{1}\right) \varepsilon_{c, s}}{f_{0}}\right]^{n}\right\}^{1 / n}}\right)\right]\right\}
$$

From the parametric study, the average value of the normalized plastic stress intercept $f_{0} / f_{c}^{\prime}$ is 0.97 with a standard deviation 0.038 . Consequently, $f_{0}$ is replaced by $f_{c}^{\prime}$.

\subsection{Ultimate Confined Concrete Stress and Strain, $f_{c c}^{\prime}$ and $\varepsilon_{c c u}$}

The ultimate confined concrete stress and strain are dependent on the unconfined compressive concrete strength $\left(f_{c}^{\prime}\right)$, the maximum lateral confining pressure due to FRP only $\left(f_{l, f, \text { max }}\right)$, the maximum lateral confining pressure due to transverse steel only $\left(f_{l, s, \text { max }}\right)$ and the ratio between the length of FRP wrap $\left(N_{f} w_{f}\right)$ and the unbraced length of the column $\left(l_{u}\right)$. Based on the regression analysis conducted on the data generated in the parametric study, the ultimate confined concrete stress $f_{c c}^{\prime}$ and strain $\varepsilon_{c c u}$ can be presented as follows

$$
\begin{aligned}
& f_{c c}^{\prime}=f_{c}^{\prime}\left[1+1.55\left(\frac{f_{l, f, \max }}{f_{c}^{\prime}}\right)\left(\frac{N_{f} w_{f}}{l_{u}}\right)^{0.3}+1.55\left(\frac{f_{l, s, \max }}{f_{c}^{\prime}}\right)\right] \\
& \varepsilon_{c c u}=\varepsilon_{c}^{\prime}\left[2.4+15\left(\frac{f_{l, f, \max }}{f_{c}^{\prime}}\right)\left(\frac{N_{f} w_{f}}{l_{u}}\right)^{0.3}+7.7\left(\frac{f_{l, s, \max }}{f_{c}^{\prime}}\right)\right] \\
& f_{l, f, \max }=\frac{2 t_{f} E_{f} \varepsilon_{f u} n_{f} w_{f} N_{f}}{D l_{u}} \\
& f_{l, s, \max }=\frac{2 A_{s t} f_{y}}{s d_{s}}
\end{aligned}
$$

where $f_{y}$ is the specified yield strength of non-prestressed steel reinforcement; $A_{s t}$ is the area of transverse steel; $d_{s}$ is the concrete core diameter to center line of transverse steel; $s$ is the center to center spacing between transverse steel; $\varepsilon_{f u}$ is the design rupture strain of FRP wrap.

\subsection{Concrete Stress and Strain at Yielding of Transverse Steel, $f_{c, s}$ and $\varepsilon_{c, s}$}

The point defined by $f_{c, s}$ and strain $\varepsilon_{c, s}$ (Fig. 8d) is the transition between the nonlinear and linear stress-strain 


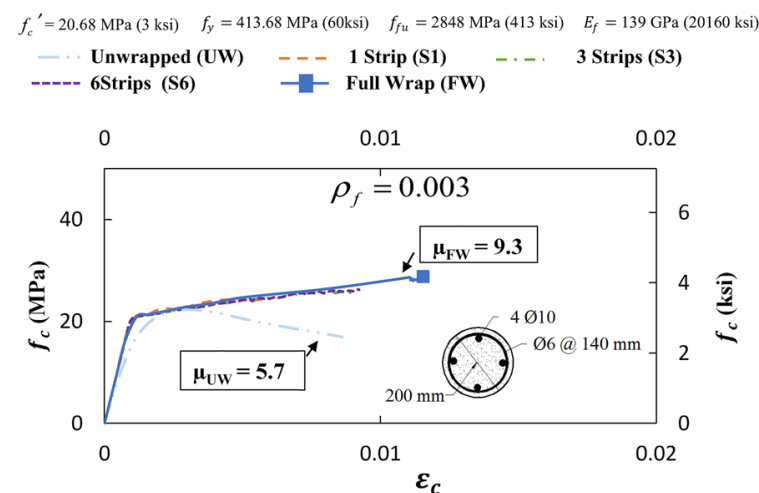

(a)

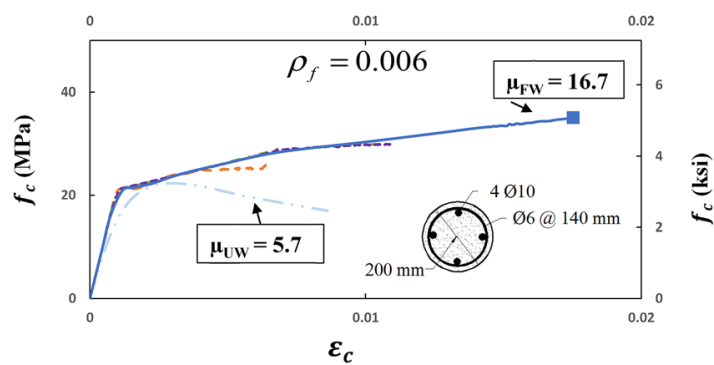

(b)

Fig. 7 Comparison of compressive stress $\left(f_{c}\right)$ versus axial strain $\left(\varepsilon_{c}\right)$ relationships for the unwrapped column and columns having the same CFRP volumetric ratio, $\rho_{\mathrm{f}} \mathbf{a} \rho_{\mathrm{f}}=0.003$ and $\mathbf{b} \rho_{\mathrm{f}}=0.006$.

relationships. The increase in the compressive strength of concrete confined by the two materials can be derived by summing the increments of the compressive strength for each material (Lee et al. 2010). Consequently, $f_{c, s}$ and $\varepsilon_{c, s}$ can be determined by summing the strength of concrete due to FRP confinement and strength of concrete due to transverse steel at yielding of the transverse steel. Considering that the transverse steel yield occurred at a lateral strain $\varepsilon_{l, y}$, then

$$
\varepsilon_{l, y}=\frac{f_{y}}{E_{s}}
$$

where $\varepsilon_{l, y}$ is the confined concrete lateral strain at yielding of transverse steel and $E_{s}$ is modulus of elasticity of the transverse steel. The strain in the confined concrete at yielding of the transverse steel may now be determined using the relationship introduced by Teng et al. (2007). for the lateral strain-axial strain relationship of FRP confined concrete where $f_{l, f y}$ is the lateral confining pressure exerted by FRP at yielding of transverse steel

$$
\begin{aligned}
& f_{l, f y}=\frac{2 t_{f} E_{f} \varepsilon_{l, y} w_{f} n_{f} N_{f}}{D l_{u}} \\
& f_{l, s, \max }^{\prime}=f_{l, s, \max } \frac{\left(1-\frac{s^{\prime}}{2 d_{s}}\right)^{2}}{1-\left(A_{s l} / A_{\text {core }}\right)}
\end{aligned}
$$

where $s^{\prime}$ is the clear spacing between the transverse steel (stirrups), and $A_{\text {core }}$ is the column core area.

The concrete core is confined by transverse steel and FRP while the concrete cover is confined by FRP only, therefore

$$
\begin{aligned}
& f_{c, s}=\frac{f_{\text {core }} A_{\text {core }}+f_{\text {cover }} A_{\text {cover }}}{A_{g}} \\
& f_{\text {core }}=f_{c, s y}+f_{c, f y}-f_{c}^{\prime} \\
& f_{\text {cover }}=f_{c, f y} \\
& A_{\text {cover }}=A_{g}-A_{\text {core }}
\end{aligned}
$$

where $A_{\text {core }}$ is the column cover area; $f_{\text {core }}$ and $f_{\text {cover }}$ are the compressive stresses of confined concrete for the column core and cover, respectively; $f_{c, f y}$ is the component of confined concrete compressive stress at yielding of transverse steel due to FRP confinement only; $f_{c, s y}$ is the component of the confined concrete compressive stress at yielding of transverse steel due to transverse steel confinement only.

Since the concrete core is confined by transverse steel and FRP, the compressive concrete stress of the column core $\left(f_{\text {core }}\right)$ can be calculated by adding the compressive concrete stress at yielding of steel due to steel confinement $\left(f_{c, s y}\right)$ and FRP confinement $\left(f_{c, f y}\right)$. Mander's model (1988) is used to calculate $f_{c, s y}$ using Eqs. (23-25). This model accounts for the effect of the compressive strength of unconfined concrete $\left(f_{c}^{\prime}\right)$ on the column's core. Teng model (2007) is used to calculate $f_{c, f y}$ using Eqs. (27-29) and it includes the effect of $f_{c}^{\prime}$ on $f_{\text {core }}$. Since both models include the effect of $f_{c}^{\prime}$ on $f_{\text {core }}$, $f_{c}^{\prime}$ is subtracted from Eq. (20) in order to avoid double counting its effect. The relationships between $f_{c, s y}$ and $f_{c}^{\prime}$, and $f_{c, f y}$ and $f_{c}^{\prime}$ are nonlinear. The nonlinearity leads to a complex model for the confined concrete stressstrain relationship. In order to simplify model, the

$$
\varepsilon_{c, s}=0.85 \varepsilon_{c}^{\prime}\left[1+8 \frac{\left(f_{l, f y}+f_{l, s, \max }^{\prime}\right)}{f_{c}^{\prime}}\right] \cdot\left\{\left[1+0.75\left(\frac{\varepsilon_{l, y}}{\varepsilon_{c}^{\prime}}\right)\right]^{0.7}-\exp \left[-7\left(\frac{\varepsilon_{l, y}}{\varepsilon_{c}^{\prime}}\right)\right]\right\}
$$




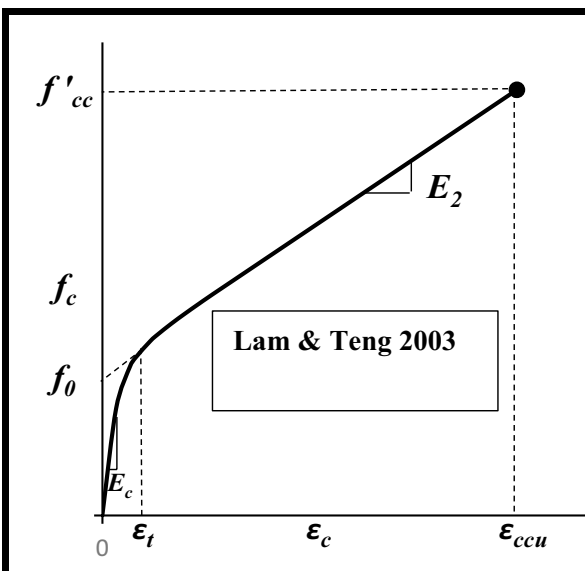

(a)

Model Considerations: Full Wrap

Model does not account for: Partial Wrap,

Longitudinal Steel, Transverse Steel, Yielding of

Transverse Steel

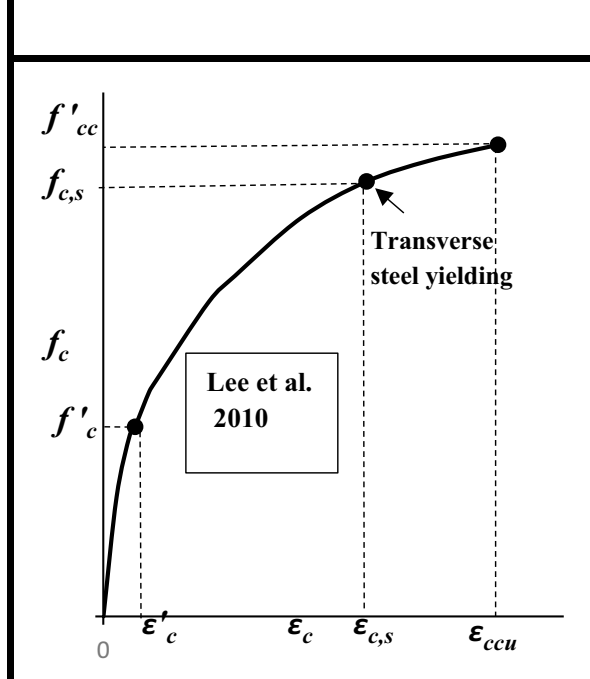

(c)

Model Considerations: Full Wrap, Transverse Steel

Yielding of Transverse Steel

Model does not account for: Partial Wrap,

Longitudinal Steel

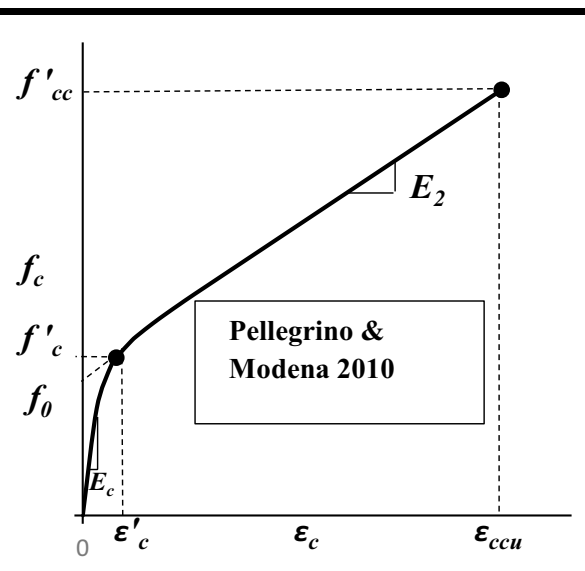

(b)

Model Considerations: Full Wrap, Partial Wrap, Longitudinal Steel, Transverse Steel (The lateral confining pressures of transverse steel and FRP are combined)

Model does not account for: Yielding of Transverse Steel

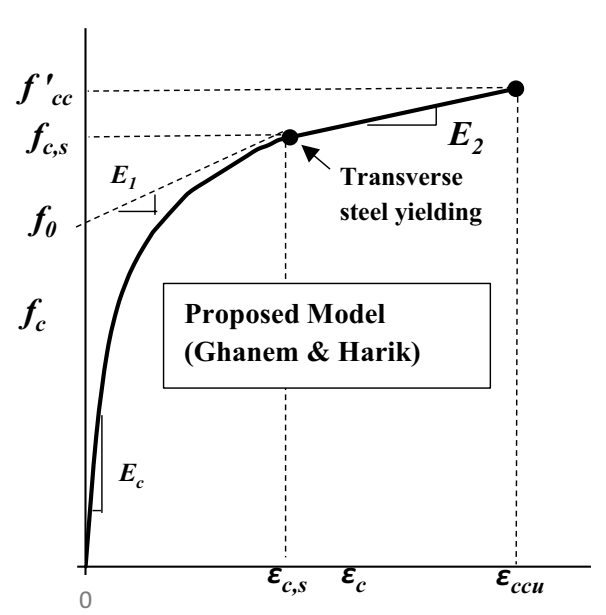

(d)

Model Considerations: Full Wrap, Partial Wrap,

Transverse Steel (The lateral confining pressures of transverse steel and FRP are treated independently),

Yielding of Transverse Steel

Model does not account for: Longitudinal Steel (Refer

to Fig. 5,6. It concluded that the increase in $\left(\rho_{\mathrm{sl}}\right)$ had little influence on concrete confinement)

Fig. 8 Confined concrete stress-strain models: a Lam \& Teng 2003, b Pellegrino \& Modena 2010, c Lee et al. 2010, and d Proposed Model.

assumption of a linear relationship generated results that are in very good agreement with experimental ones (Demers and Neale 1999; Rocca et al. 2006; Varma et al. 2009; Lee et al. 2010). Consequently, a linear relationship between $f_{c, s y}$ and $f_{c}^{\prime}$, and $f_{c, f y}$ and $f_{c}^{\prime}$ is adopted in the proposed model.
Mander's model (1988) is used to calculate stress of confined concrete due to transverse steel

$$
f_{c, s y}=\frac{f_{c c, s}^{\prime}\left(\varepsilon_{c, s} / \varepsilon_{c c u, s}\right) r_{s}}{r_{s}-1+\left(\varepsilon_{c, s} / \varepsilon_{c c u, s}\right)^{r_{s}}}
$$


Table 4 Stress-strain models for FRP confined concrete.

\begin{tabular}{|c|c|}
\hline Lam and Teng (2003) & Pellegrino and Modena (2010) \\
\hline 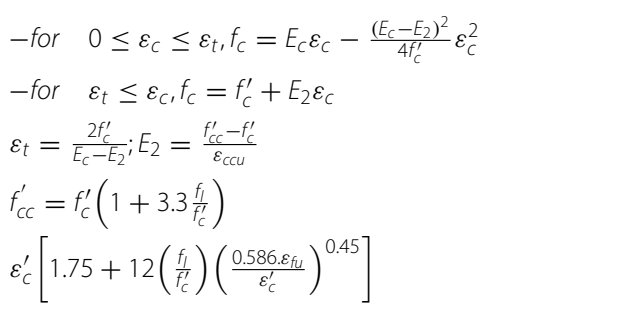 & 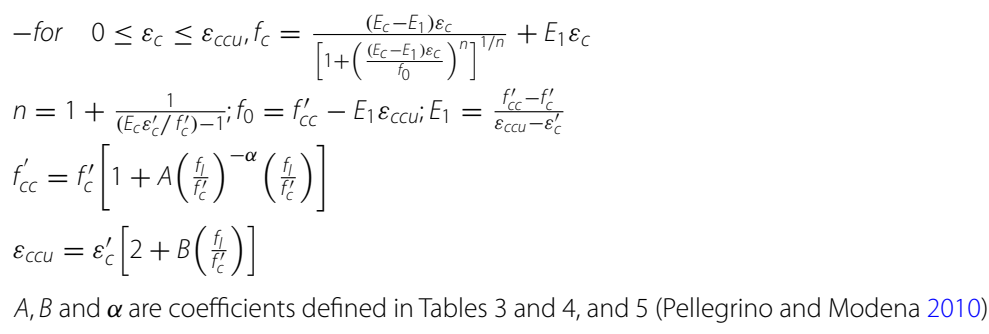 \\
\hline Lee et al. (2010) & Proposed model (Ghanem and Harik) \\
\hline 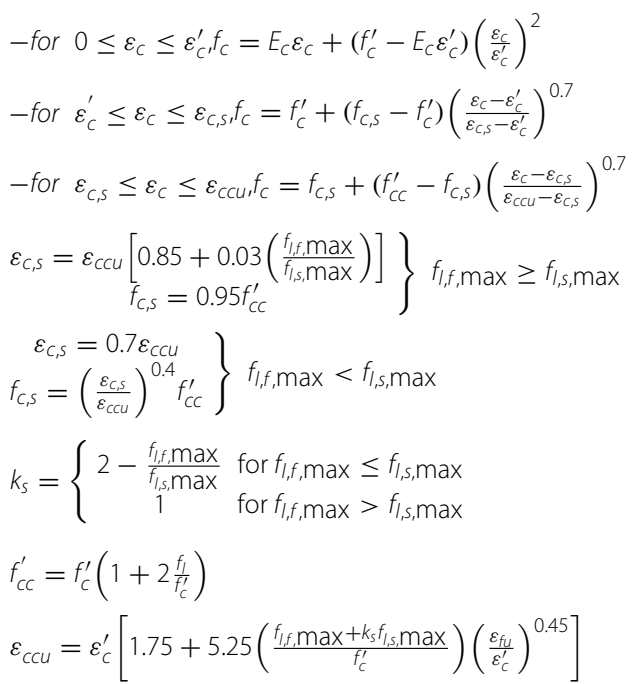 & 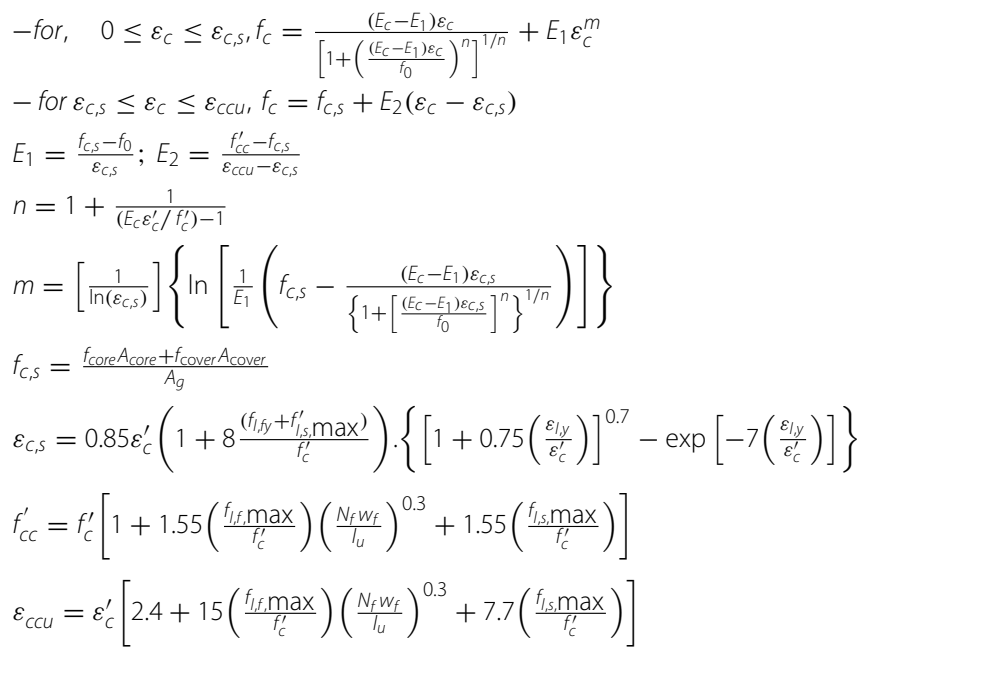 \\
\hline
\end{tabular}

in which $r_{s}$ is a constant to account for the brittleness of concrete and is determined by Mander et al. (1988)

$$
r_{s}=\frac{E_{c}}{E_{c}-f_{c c, s}^{\prime} / \varepsilon_{c c u, s}}
$$

where $f_{c c, s}^{\prime}$ and $\varepsilon_{c c u, s}$ are the peak compressive stress and strain, respectively, of confined concrete under the transverse steel confining pressure at yielding of transverse steel and can be calculated using the following equations (Mander et al. 1988).

$$
\begin{aligned}
& f_{c c, s}^{\prime}=f_{c}^{\prime}\left(2.254 \sqrt{1+7.94 \frac{f_{l, s, \max }^{\prime}}{f_{c}^{\prime}}}-2 \frac{f_{l, s, \max }^{\prime}}{f_{c}^{\prime}}-1.254\right) \\
& \varepsilon_{c c u, s}=\varepsilon_{c}^{\prime}\left[1+5\left(\frac{f_{c c, s}^{\prime}}{f_{c}^{\prime}}\right)\right]
\end{aligned}
$$

The confined concrete stress due to FRP, $f_{c, f y}$, can be expressed as follows

$$
f_{c, f y}=\frac{f_{c c, f}^{\prime}\left(\varepsilon_{c, s} / \varepsilon_{c c u, f}\right) r_{f}}{r_{f}-1+\left(\varepsilon_{c, s} / \varepsilon_{c c u, f}\right)^{r_{f}}}
$$

in which, $r_{f}$ is a constant that accounts for the brittleness of concrete and can be calculated as Mander et al. (1988)

$$
r_{f}=\frac{E_{c}}{E_{c}-f_{c c, f}^{\prime} / \varepsilon_{c c u, f}}
$$

where $f_{c c, f}^{\prime}$ and $\varepsilon_{c c u, f}$ are the peak compressive stress and strain, respectively, of FRP confined concrete at yielding of transverse steel. They can be determined using the following equations (Teng et al. 2007)

$$
f_{c c, f}^{\prime}=f_{c}^{\prime}\left(1+3.5 \frac{f_{l, f y}}{f_{c}^{\prime}}\right)
$$




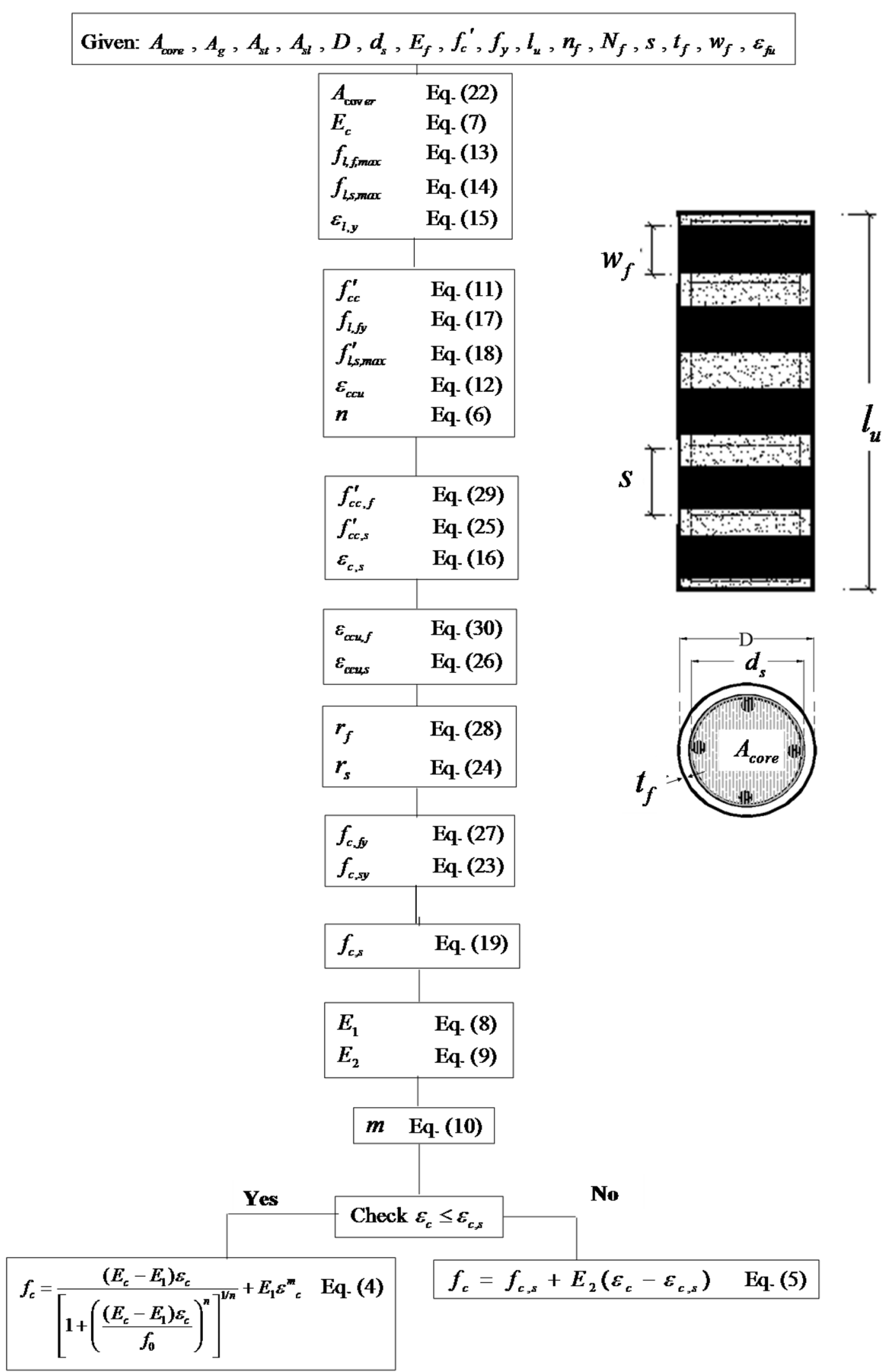

Fig. 9 Summary of the proposed confined concrete stress-strain model. 


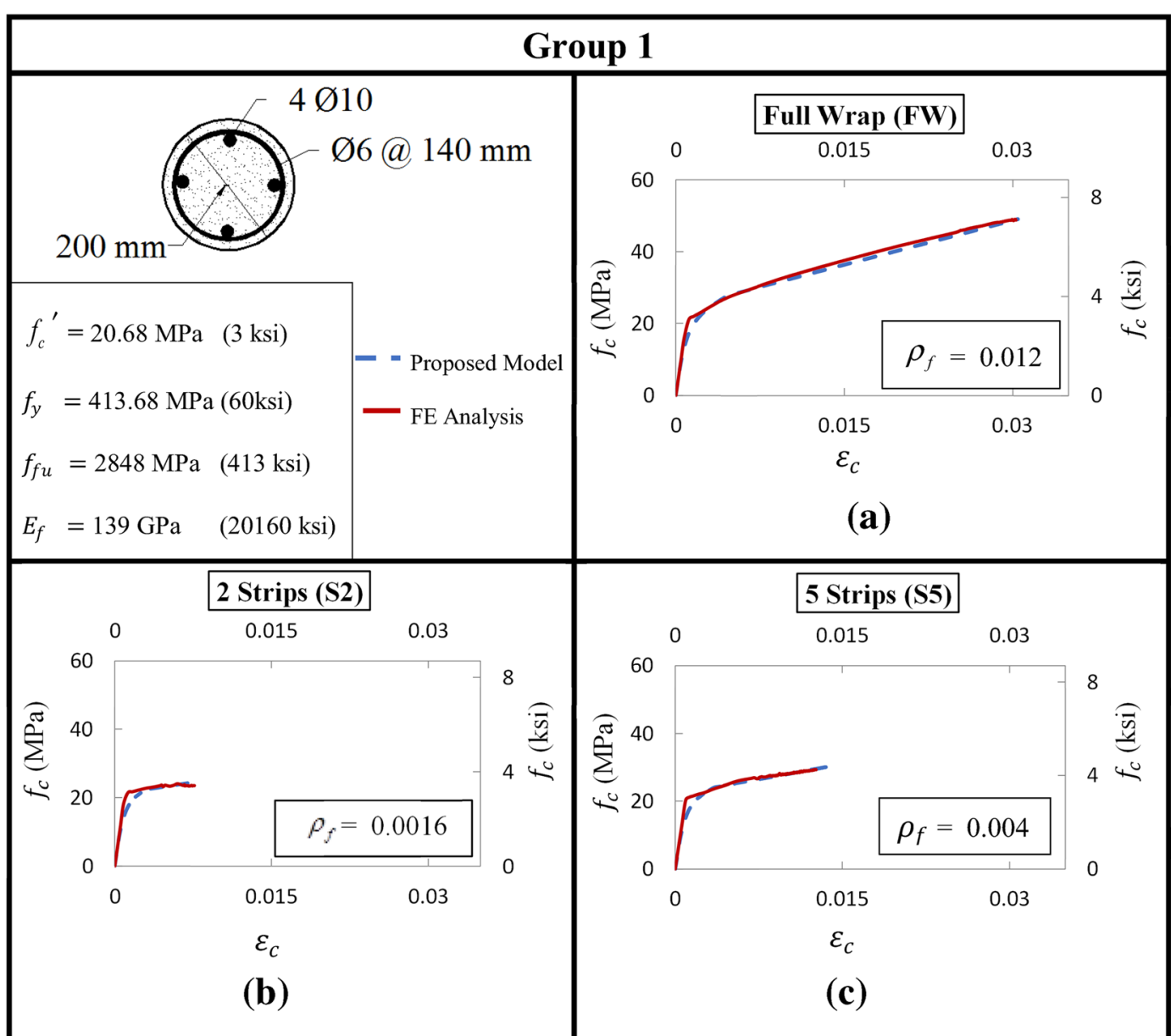

Fig. 10 Comparison between the proposed model and FE compressive $\left(f_{c}\right)$ versus axial strain $\left(\varepsilon_{c}\right)$ for Group 1: a fully wrapped (FW in Fig. 2) column, b column with 2 strips (S2 in Fig. 2), and c column with 5 strips (S5 in Fig. 2).

$$
\varepsilon_{c c u, f}=\varepsilon_{c}^{\prime}\left[1+17.5\left(\frac{f_{l, f y}}{f_{c}^{\prime}}\right)\right]
$$

A summary of the proposed confined concrete stressstrain model is presented in Fig. 9.

\section{Comparison of Proposed Model with FE and Experimental Results}

A comparison between the proposed confined concrete stress-strain model and the finite element model is presented in Fig. 10 for RC columns in Group 1 that are partially and fully wrapped with FRP. The comparison shows that, as the stress approaches the ultimate confined compressive concrete stress, the model accurately predicts the overall behavior of the columns as well as stress and strain at ultimate.

The proposed model is also compared with experimental results for fully wrapped circular columns in Fig. 11
(Demers and Neale 1999; Lee et al. 2010) and partially wrapped columns (Rocca et al 2006; Varma et al. 2009) in Fig. 12. The results are also compared with ones generated from the three models presented in Tables 4 (Lam and Teng 2003; Lee et al. 2010; Pellegrino and Modena 2010). Except for column U25-2 (Demers and Neale 1999) in Fig. 11b, the proposed model predicted the stress at ultimate for fully and partially wrapped columns. The other models overestimated the stress at ultimate for all columns. Figures 11 and 12 show that the consideration of yielding of transverse steel in the model leads to better prediction of the column behavior beyond that point. Although the model by Pellegrino and Modena (2010) accounts for the transverse steel, its influence cannot be separated from that of the FRP strips since the total lateral confining pressure, $f_{l}$, combines the transverse steel and FRP pressures while the proposed model treats them independently. 


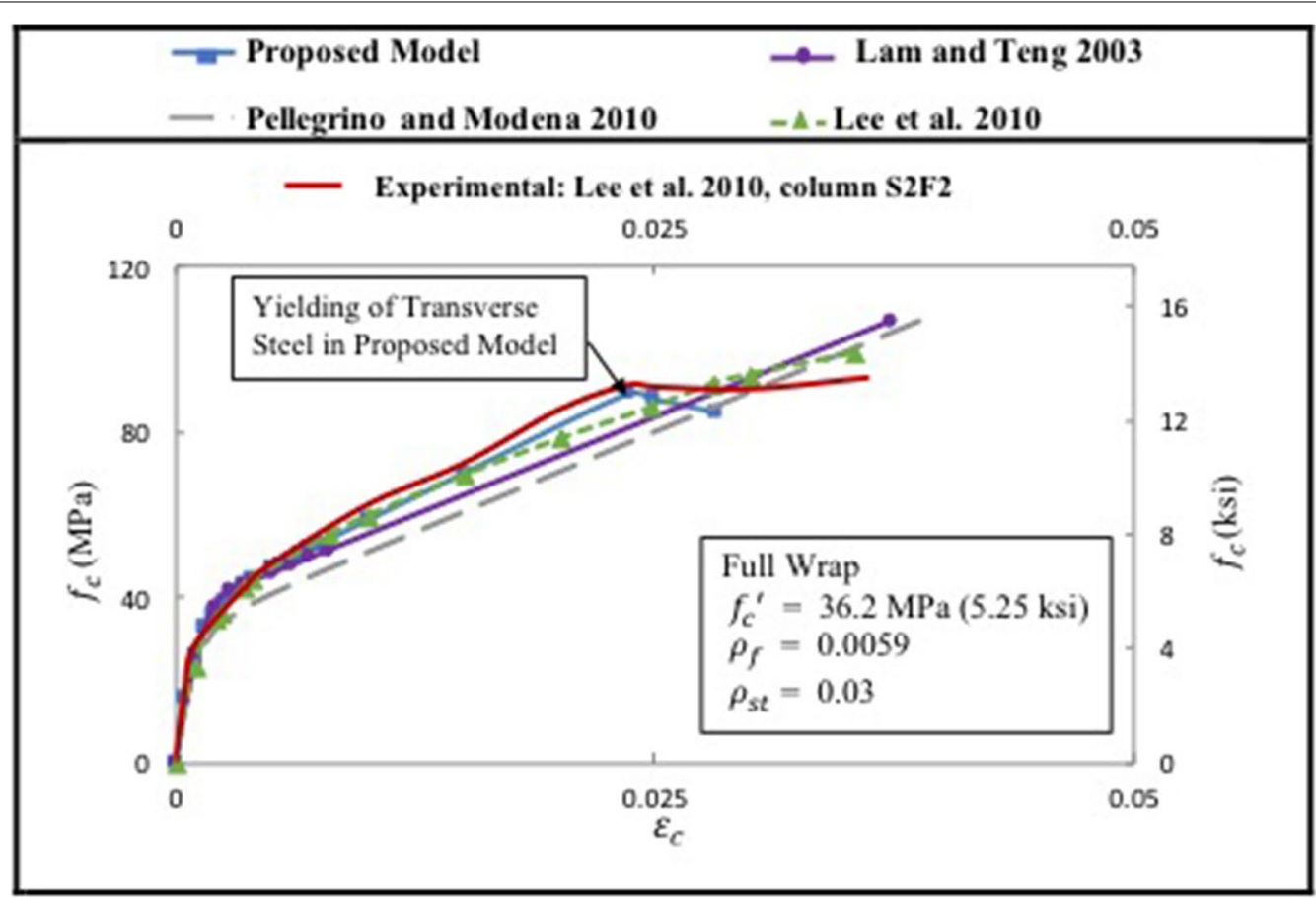

(a)

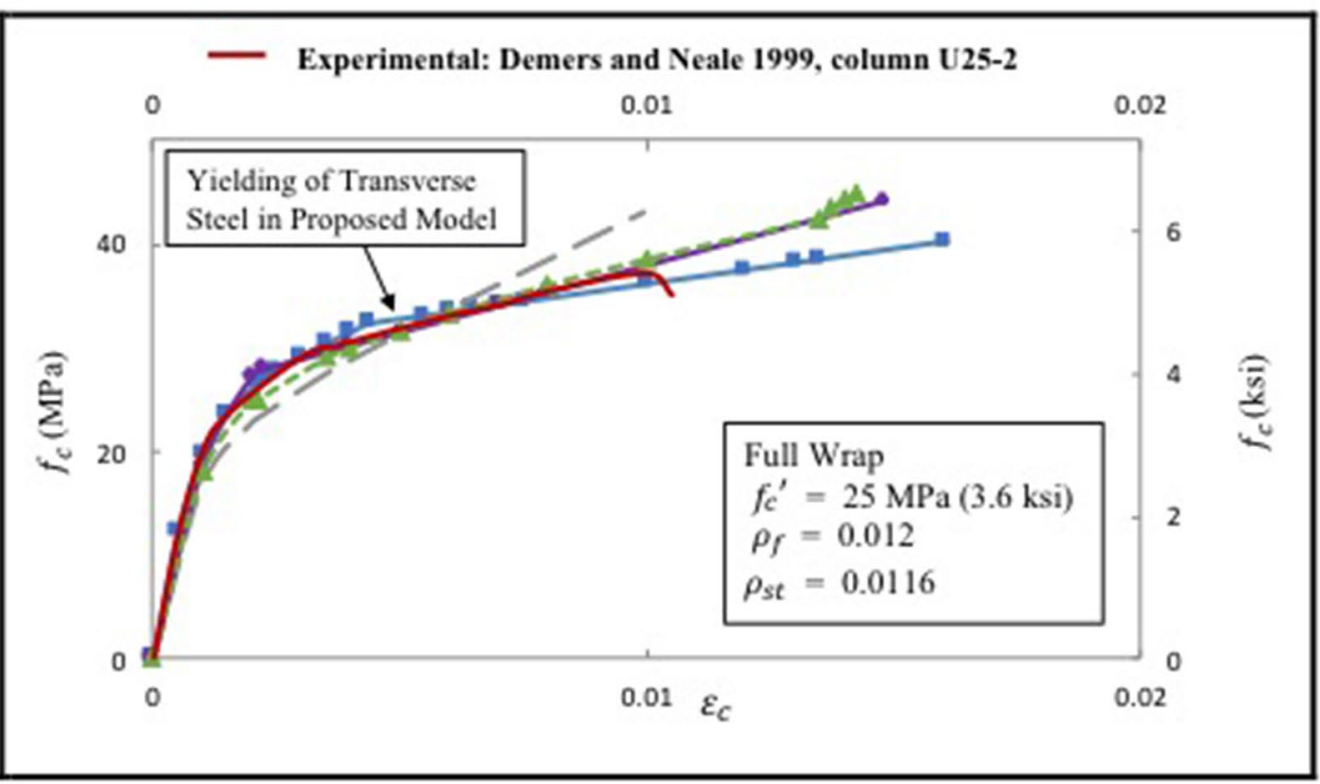

(b)

Fig. 11 Comparison between the proposed model and experimental compressive stress $\left(f_{c}\right)$ versus axial strain $\left(\varepsilon_{c}\right)$ for fully wrapped circular RC columns.

\section{Conclusions}

This paper evaluated the effectiveness of partial wraps (or strips) and proposed an analytical model for describing the compressive behavior of RC columns that are partially and fully wrapped with FRP. Three-dimensional finite element (FE) models were generated to study the influence, on the behavior of the concentrically loaded columns, of the unconfined compressive strength $\left(f_{c}^{\prime}\right)$, the number of 


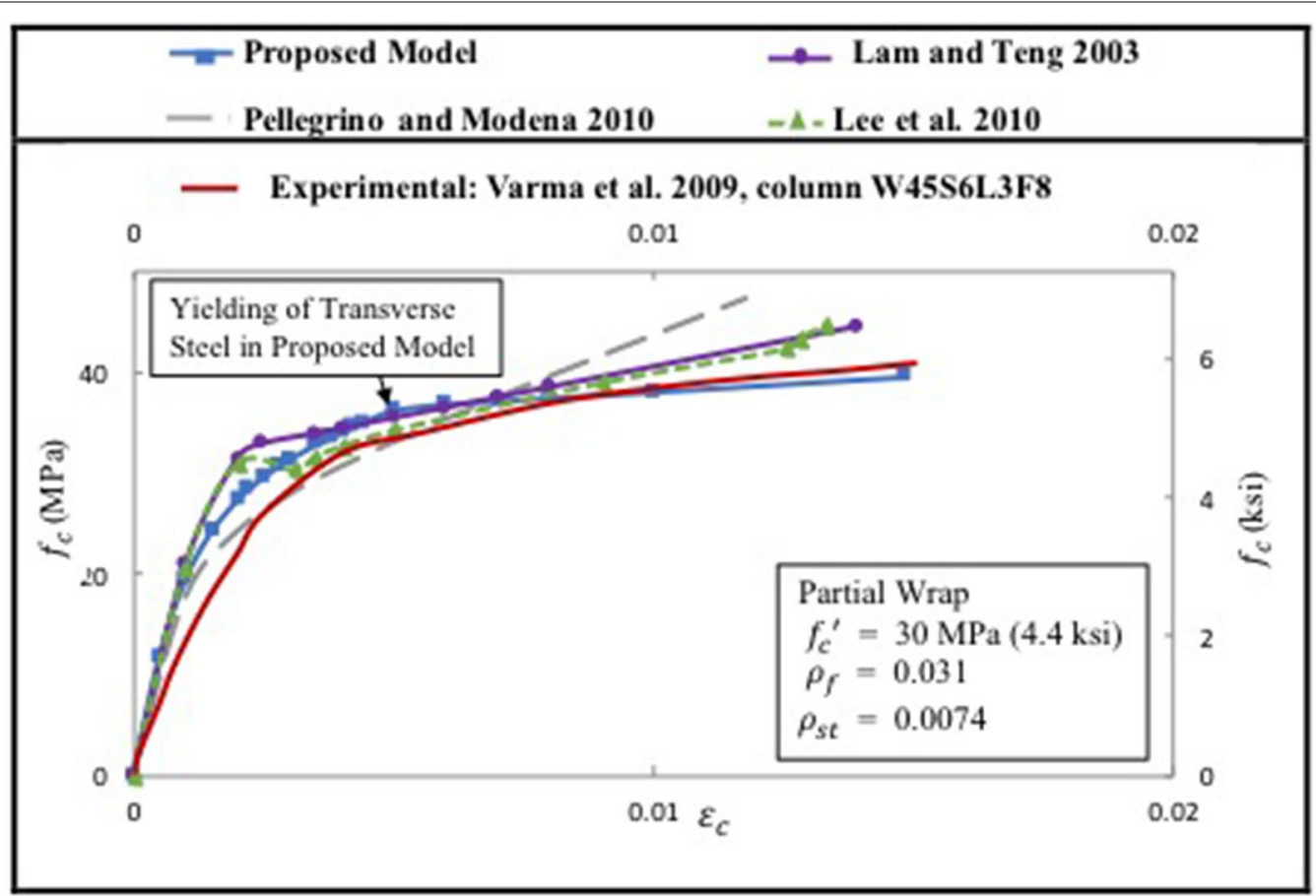

(a)

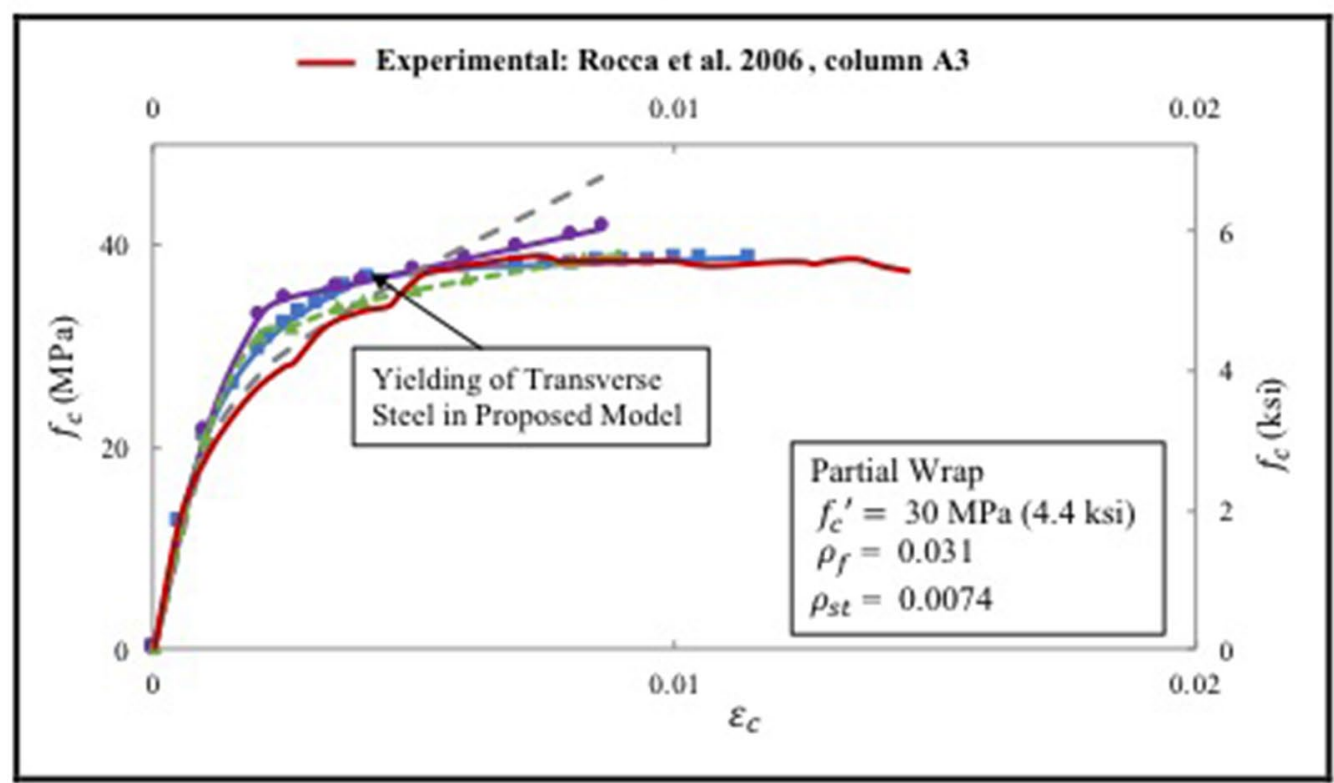

(b)

Fig. 12 Comparison between the proposed model and experimental compressive stress $\left(f_{c}\right)$ versus axial strain $\left(\varepsilon_{c}\right)$ for partially wrapped circular RC columns.

strips $\left(N_{f}\right)$, the FRP volumetric ratio $\left(\rho_{f}\right)$, the transverse steel reinforcement ratio $\left(\rho_{s t}\right)$, and the longitudinal steel reinforcement ratio $\left(\rho_{s l}\right)$. It should be noted that the columns wrapped with one, two, or three strips are not of practical interest and are used herein to illustrate the influence of partial wrapping as the analysis transitions from an unwrapped column to a partially wrapped column with one to seven strips, to a fully wrapped column.

For the columns evaluated in this paper, the parametric study indicated the following: 
(1) The influence of increasing the unconfined compressive strength $\left(f_{c}^{\prime}\right)$ has a pronounced effect on the increase in the confined concrete compressive strength $\left(f_{c c}^{\prime}\right)$

(2) As the number of identical strips increases (or $\rho_{f}$ increases), the influence of the transverse steel confinement $\left(\rho_{s t}\right)$ decreases

(3) The contribution of the longitudinal steel has little influence on the confined concrete stress-strain behavior

(4) The increase in the number of strips $\left(N_{f}=1-7\right)$, while keeping the FRP volumetric ratio $\left(\rho_{f}\right)$ constant, leads to an increase in the ultimate compressive stress, strain and ductility. This indicates that, for a specific $\rho_{f}$ it is more effective to fully wrap the column in order to increase the ultimate confined concrete compressive stress and axial strain.

Based on the parametric study, a new model is proposed for the confined concrete compressive stress and axial strain in partially and fully wrapped columns. The primary advantage of the model is its separate account of the yielding of transverse steel, which influences the behavior of the stress-strain relationship beyond that point. Compared to experimental data on partially and fully wrapped columns, the proposed model was capable of predicting the stress at ultimate while the other models overestimated its magnitude.

\section{Authors' contributions}

SYG and IEH contributed to the design and implementation of the research, the analysis of the results and the writing of the manuscript. Both authors read and approved the final manuscript.

\section{Author details}

${ }^{1}$ Morehead State University, Engineering and Technology Management, Morehead, KY 40351, USA. ${ }^{2}$ Department of Civil Engineering, University of Kentucky, Lexington, KY 40506, USA.

\section{Publisher's Note}

Springer Nature remains neutral with regard to jurisdictional claims in published maps and institutional affiliations.

Received: 13 March 2017 Accepted: 28 May 2018

Published online: 30 July 2018

\section{References}

ACl 318-11. (2011). Building Code Requirements for Structural Concrete. Farmington: American Concrete Institute.

ANSYS. (2012). ANSYS Academic Research, Release 14.0. Canonsburg: ANSYS, Inc.

Barros, J., \& Ferreira, D. (2008). Assessing the efficiency of CFRP discrete confinement systems for concrete cylinders. Journal of Composites for Construction, 12(2), 134-148.

Cui, C., \& Sheikh, S. (2010). Experimental study of normal- and high-strength concrete confined with fiber-reinforced polymers. Journal of Composites for Construction, 14(5), 553-561.
Demers, M., \& Neale, K. W. (1999). Confinement of reinforced concrete columns with fiber-reinforced composite sheets-an experimental study. Canadian Journal of Civil, 26(2), 226-241.

El Fattah, A. M. A., \& Rasheed, H. A. (2015). Numerical Procedure to Generate Interaction Diagrams for Circular Concrete Columns Wrapped with FRP. ACl Special Publication, 301, 1-20.

Hawileh, R., El-Maaddawy, T. A., \& Naser, M. (2012). Non-linear finite element modeling of concrete deep beams with openings strengthened with externally-bonded composites. Materials \& Design, Elsevier, 42, 378-387.

Hawileh, R., Naser, M., \& Abdalla, J. A. (2013). Finite element simulation of reinforced concrete beams externally strengthened with short-length CFRP plates. Composites Part B: Engineering, Elsevier, 45(1), 1722-1730.

Lam, L., \& Teng, J. G. (2003). Design-oriented stress-strain model for FRPconfined concrete. Construction and Building Materials, 17, 471-489.

Lee, J.-Y., Kim, J.-K., Yi, C.-K., Jeong, H.-S., \& Kim, S.-W. (2010). Compressive response of concrete confined with steel spirals and FRP composites. Journal of Composite Materials, 44(4), 481-504.

Mander, J. B., Priestley, M. J. N., \& Park, R. (1988). Theoretical stress-strain model for confined concrete. Journal of Structural Engineering, 114(8), 1804-1826.

Mirmiran, A., \& Shahawy, M. (1997). Behavior of concrete columns confined by fiber composites. Journal of Structural Engineering, 123(5), 583-590.

Mirmiran, A., Zagers, K., \& Yuan, W. (2000). Nonlinear finite element modeling of concrete confined by fiber composites. Finite Elements in Analysis and Design, 35(1), 79-96.

Nanni, A., \& Bradford, N. M. (1995). FRP jacketed concrete under uniaxial compression. Construction and Building Materials, 9(2), 115-124.

Pellegrino, C., \& Modena, C. (2010). Analytical model for FRP confinement of concrete columns with and without internal steel reinforcement. Journal of Composites for Construction, 14(6), 693-705.

Richard, R. M., \& Abbott, B. J. (1975). Versatile elastic-plastic stress strain formula. Journal of the Engineering Mechanics Division., 101(4), 511-515.

Rocca, S., Galati, N., Nanni, A. (2006) Large-Size Reinforced Concrete Columns Strengthened with Carbon FRP: Experimental Evaluation. Third International Conference on FRP Composites in Civil Engineering (CICE 2006), Miami, $\mathrm{FL}, \mathrm{USA}$.

Saadatmanesh, H., Ehsani, M. R., \& Li, M. W. (1994). Strength and ductility of concrete columns externally reinforced with fiber composite straps. ACI Structural Journal, 91(4), 434-447.

Teng, J. G., Huang, Y. L., Lam, L., \& Ye, L. P. (2007). Theoretical model for fiberreinforced polymer-confined concrete. Journal of Composites for Construction, 11(2), 201-210.

Toutanji, H. (1999). Stress-strain characteristics of concrete columns externally confined with advanced fiber composite sheets. ACI Material Journal, 96(3), 397-404.

Varma, R. K., Barros, J. A. O., \& Sena-Cruz, J. M. (2009). Numerical model for CFRP confined concrete elements subject to monotonic and cyclic loadings. Composites: Part B, 40(8), 766-775.

Wu, H., Wang, Y., Liu, Y., \& Li, X. (2009). Experimental and computational studies on high-strength concrete circular columns confined by aramid fiberreinforced polymer sheets. Journal of Composites for Construction, 13(2), 125-134.

\section{Submit your manuscript to a SpringerOpen ${ }^{\odot}$ journal and benefit from:}

- Convenient online submission

- Rigorous peer review

- Open access: articles freely available online

- High visibility within the field

- Retaining the copyright to your article

Submit your next manuscript at springeropen.com 